\title{
Crashworthiness optimisation of a composite energy- absorbing structure for subway vehicles based on hybrid particle swarm optimisation
}

DOI:

10.1007/s00158-018-2022-3

\section{Document Version}

Accepted author manuscript

Link to publication record in Manchester Research Explorer

Citation for published version (APA):

Xie, S., Li, H., Yang, C., \& Yao, S. (2018). Crashworthiness optimisation of a composite energy-absorbing structure for subway vehicles based on hybrid particle swarm optimisation. Structural and Multidisciplinary Optimization. https://doi.org/10.1007/s00158-018-2022-3

Published in:

Structural and Multidisciplinary Optimization

\section{Citing this paper}

Please note that where the full-text provided on Manchester Research Explorer is the Author Accepted Manuscript or Proof version this may differ from the final Published version. If citing, it is advised that you check and use the publisher's definitive version.

\section{General rights}

Copyright and moral rights for the publications made accessible in the Research Explorer are retained by the authors and/or other copyright owners and it is a condition of accessing publications that users recognise and abide by the legal requirements associated with these rights.

\section{Takedown policy}

If you believe that this document breaches copyright please refer to the University of Manchester's Takedown Procedures [http://man.ac.uk/04Y6Bo] or contact uml.scholarlycommunications@manchester.ac.uk providing relevant details, so we can investigate your claim.

\section{OPEN ACCESS}




\title{
Crashworthiness optimisation of a composite energy-absorbing structure for subway vehicles based on hybrid particle swarm optimisation
}

\author{
Suchao Xie ${ }^{\mathrm{a}, \mathrm{c}}$ Haihong $\mathrm{Li}^{\mathrm{a}, \mathrm{c}}$ Chengxing Yang ${ }^{\mathrm{b}}$, Shuguang Yao ${ }^{\mathrm{a}, \mathrm{c}}$ \\ ${ }^{a}$ Key Laboratory of Traffic Safety on Track (Central South University), Ministry of Education, Changsha 410075 , \\ China; \\ ${ }^{b}$ School of Mechanical, Aerospace and Civil Engineering, University of Manchester, Pariser Building, Manchester \\ M13 9PL, UK; \\ ${ }^{c}$ School of Traffic \& Transportation Engineering, Central South University, Changsha 410075, China;
}

\begin{abstract}
To improve the crashworthiness of subway vehicles, a composite energy-absorbing structure (EAS) is designed by coupling a thin-walled metal tube and aluminium honeycomb structures. On this basis, the effectiveness of the composite structure and aluminium honeycomb finite element model (FEM) is validated by conducting trolley impact tests and quasi-static compression experiments. Based on the verified FEM, the surrogate models, including polynomial response surface (PRS), Kriging, radial basis function (RBF) and supported vector regression (SVR), are established to get the relationship between crashworthiness indexes and design variables. Then, the most accurate model is employed for crashworthiness optimisation through comparing the accuracies of these four models. Owing to the mutually effects among components of the composite EAS and the relatively complex mathematical formulae acquired by the high-precision surrogate model, a hybrid particle swarm optimisation (HPSO) algorithm is put forward. The performance of the HPSO is tested by a typical engineering optimization case. The results indicate that the HPSO algorithm presents various advantages (e.g. strong global search ability, high optimisation accuracy, etc.). By optimising the mathematical model of the composite EAS, the optimal configurations of the structure are obtained, which confirms that the HPSO algorithm has favourable applicability and performance in the crashworthiness optimisation of the EASs for subway vehicles.
\end{abstract}

Keywords: Composite energy-absorbing structure; Impact test; Surrogate model; Hybrid particle swarm optimisation; Global search

* Corresponding author. E-mail: Chengxing_Yang_Hn@163.com. 


\section{Introduction}

To improve the safety of passengers during the subway crash accidents, the vehicles have to be designed with good crashworthiness. Otherwise, the casualties and loss of property resulting from collision accidents are unbearable. For example, on 22 November, 2012, a subway in Pusan, South Korea broke down and then the following subway train crashed into it at high speed, causing the occurrence of a rear-end collision with over 100 casualties. To reduce the loss caused by such collisions, it is necessary to install energy-absorbing structures (EASs) on the front end of subway vehicles.

Subway vehicles running on the fixed tracks are generally marshalled as a six-car train, which are high quality, high-energy level, high-capacity, self-guided vehicles which can generate a significant amount of initial kinetic energy compared with that of automobiles. Therefore, the EAS on the subway vehicles are required to show high collision resistances to meet passive safety protection requirements. Many investigations have concerned themselves with the structural crashworthiness design of subway vehicles. Xie and Zhou (2014) proposed the design concept of a crashworthy subway vehicle based on the characteristics of subway vehicles and divided energy-absorbing process of the head car (HC) impact into four steps. Moreover, they designed the energy-absorption structures on the basis of the impact analysis of a square thin-walled structure. To improve the impact performance of honeycomb-filled structures under eccentric loading for subway vehicles, Yao et al. (2018) conducted an optimisation that the cross-sectional shape of the guide was changed based on the bending strength and found that no instability phenomenon arose in the improved structure. Xie and Zhou (2014) designed a composite EAS for a certain subway vehicle to meet the requirements for passive safety protection during railway vehicle collisions. Peng et al. (2015) presented a composite EAS mainly composed of a square tube and aluminium honeycomb structure for use in subway vehicles and discussed its collision performance: they found that a structural form that can induce more regular folding buckling will promote the energy absorption and crashworthiness of a structure.

To date, many scholars have carried out testing, simulation, and theoretical research on different EASs composed of thin-walled tubes or aluminium honeycombs (Li et al. 2018; Peng et al. 2017; Sun et al. 2017; Xie and Zhou 2015; Zeng and Duddeck 2017; Duddeck et al. 2016). A 
favourable energy absorbing structure is able to absorb, or dissipate, all initial kinetic energy in a controllable manner. Thin-walled mental structures were extensively investigated owing to their low cost and advantageous energy-absorbing efficiency (Alavi Nia et al. 2012; Chen et al. 2017; Chen et al. 2018; Kohar et al. 2015; Alavi Nia and Parsapour 2013). In addition, aluminium honeycomb with its high strength-weight ratio and high energy absorption efficiency has been widely applied in EASs (Zhu et al. 2016; Sun et al. 2016; Wang et al. 2014; Yamashita and Gotoh 2005). Researchers throughout the world have studied the energy-absorbing characteristics of combining thin-walled metal structures with cellular honeycomb structures, because the composite EASs are capable of absorbing adequate energy during the collision process. Wang et al. (2016) investigated matching relationships between the inside honeycomb core and outside metallic thin-walled structures and carried out parametric simulations to understand further the matching effect. They found that deformation mode evolution of the honeycomb-filled thin-walled square tube (HFST) structures is closely related to the structural geometric configuration. Zhou et al. (2017) designed the energy-absorbing structure of a crashworthy railway vehicle by combining the characteristics of thin-walled metal structures and aluminium honeycomb structures, and they discussed the safe velocity standard for rail vehicle collisions, which was improved from $25 \mathrm{~km} / \mathrm{h}$ to $45 \mathrm{~km} / \mathrm{h}$ by adopting a combined energy-absorbing structure. Hussein et al. (2017) conducted experimental investigations aimed to studying the axial crushing behaviour of square aluminium tubes with different configurations. The results show square aluminium tubes filled with both polyurethane foam and aluminium honeycomb is the most crashworthy combination.

Basically, the main challenge in the crashworthiness design and development of subway vehicles is how to find the optimal design of an EAS that can satisfy best the crashworthiness requirements. Optimisation of structural crashworthiness using surrogate models and intelligent algorithms is considered as a research focus in vehicle engineering (Fazilati and Alisadeghi 2016; Sun et al. 2017; Yin et al. 2013; Forsberg and Nilsson 2005; Yin et al. 2014). In aims to address the energy absorption behaviour and crashworthiness optimisation of short length circular tubes under quasi-static lateral loading, Baroutaji et al. (2015) adopted the response surface methodology (RSM) and multi-objective optimisation design (MOD) to find the optimal configuration of a range of proposed energy absorption structures. Song et al. (2013) performed a comparative study of four surrogate models including PRS, Kriging, SVR, and RBF and used 
sequential quadratic programming (SQP) and particle swarm optimisation (PSO) for these models to find the optimal results, respectively. Xie et al. (2018) demonstrated the crashworthiness optimisation of a composite EAS for railway vehicles based on the polynomial response surface (PRS) method and PSO. Yang and Qi (2013) employed a multi-objective particle swarm optimisation (MOPSO) algorithm to generate the Pareto fronts for different MOD problems under oblique impact on the basis of Kriging meta-models constructed using finite element analysis (FEA) results. To design lightweight automobile parts and decrease their fuel consumption, Gao et al. (2018) proposed a cylindrical negative Poisson's ratio (NPR) structure based on the double-V unit cell. Then, they established a Kriging approximation model and operated the MOPSO algorithm to achieve an optimal cylindrical NPR structure. To improve the crashworthiness of a gradual EAS for subway vehicles, $\mathrm{Xu}$ et al. (2016) addressed a new cut-out groove design and used optimisation technology with the response surface (RS) method and adaptive simulated annealing (ASA) algorithm to find optimal structure.

Many scholars have mainly focused their investigations on optimising thin-walled metal tubes or foam-filled thin-walled metal tubes installed on railway vehicles or automobiles; however, the crashworthiness optimisation, in most of the literature, is implemented by employing a single surrogate model and existing heuristic algorithms, which may not guarantee that the chosen surrogate model was necessarily capable of leading to the best fitness and the relatively complex expressions obtained on the basis of surrogate methods may cause local optimum when using certain algorithms. The optimisation of the EASs coupling thin-walled metal tubes and aluminium honeycomb structures using the improved PSO has rarely been investigated. The current project presents a composite EAS used for subway vehicle and studies the crash performance. Based on the validated FEM of the composite EAS, crashworthiness optimisation was conducted by the high-precision surrogate model and a hybrid particle swarm optimisation (HPSO) algorithm, in an attempt to provide a theoretical basis for the optimisation of the crashworthiness of composite EASs for subway vehicles. 


\section{Numerical analyses}

\subsection{Optimisation index for crashworthiness}

According to the literature (Yin et al. 2015; Djamaluddin et al. 2015), the crashworthiness behaviour of a structure was evaluated based on various indexes including specific energy absorption $(S E A)$, peak crushing force $\left(F_{p}\right)$, average crushing force $\left(F_{\text {avg }}\right)$, and crash force efficiency $(C F E) . S E A$ is an important index used for measuring the energy absorption capacity of a structure, which is equal to the energy absorbed of structure per unit mass during the collision process, as shown in Formula (1):

$$
S E A=\frac{E A}{m}=\frac{\int_{0}^{s} F(x) d x}{m}
$$

where, $F, s$, and $m$ refer to the crash force, the compression displacement, and the total mass of a structure, respectively.

$F_{a v g}$ is used to measure the capacity of buffering deformation for EASs, which can be acquired by employing energy absorption (EA) divided by the compression displacement $s$, as shown in Formula (2):

$$
F_{\text {avg }}=\frac{E A(s)}{s}
$$

$C F E$, also called the utilisation rate of load, is the ratio of $F_{a v g}$ of a structure to $F_{p}$. The larger the $C F E$, the more steady the crash force of the structure, as shown in Formula (3):

$$
C F E=\frac{F_{a v g}}{F_{p}}
$$

Additionally, the initial peak crushing force $\left(F_{i p}\right)$ needs to be considered. If $F_{i p}$ exceeds a certain threshold, a large initial deceleration will be induced to threaten the safety of passengers. Therefore, it is necessary to reduce $F_{i p}$ as far as possible.

\subsection{Numerical simulation}

\subsubsection{Design of the composite EAS}

The composite EAS designed in the study is illustrated in Fig. 1. The EAS is installed at two sides of front end of the underframe of subway vehicles, which is mainly composed of a 
quadrate-tapered thin-walled tube, aluminium honeycomb, diaphragm for isolation from the honeycombs, front-and back-end plates and guide crossing the centre of the diaphragms and connecting with the front-end plate. Fig. 1 shows the compositions and sizes of components of the structure: the length and thickness of quadrate-tapered thin-walled tube are $787 \mathrm{~mm}$ and $2.5 \mathrm{~mm}$, respectively, whose two sides stand the front-and back-end plates with rectangular sections. The cross-sectional areas of the two plates are $280 \mathrm{~mm} \times 188 \mathrm{~mm}$ and $280 \mathrm{~mm} \times 232 \mathrm{~mm}$, respectively. An inducement groove with $40 \mathrm{~mm}$ radius is located near the front-end plate to prevent from excessive initial peak crushing force. The internal part of the quadrate-tapered thin-walled tube contains two types of aluminium honeycombs which are separated by the diaphragms, and these honeycombs are called type A and B type with the same cross-sectional dimensions of $150 \mathrm{~mm} \times$ $90 \mathrm{~mm}$ and the different axial dimensions of $97 \mathrm{~mm}$ and $62 \mathrm{~mm}$, respectively. The configuration of the aluminium honeycombs can prevent the structure from instability under axial loads. There are nine diaphragms, each of $3 \mathrm{~mm}$, in thickness in the composite EAS and each diaphragm is welded to the quadrate-tapered thin-walled tube.

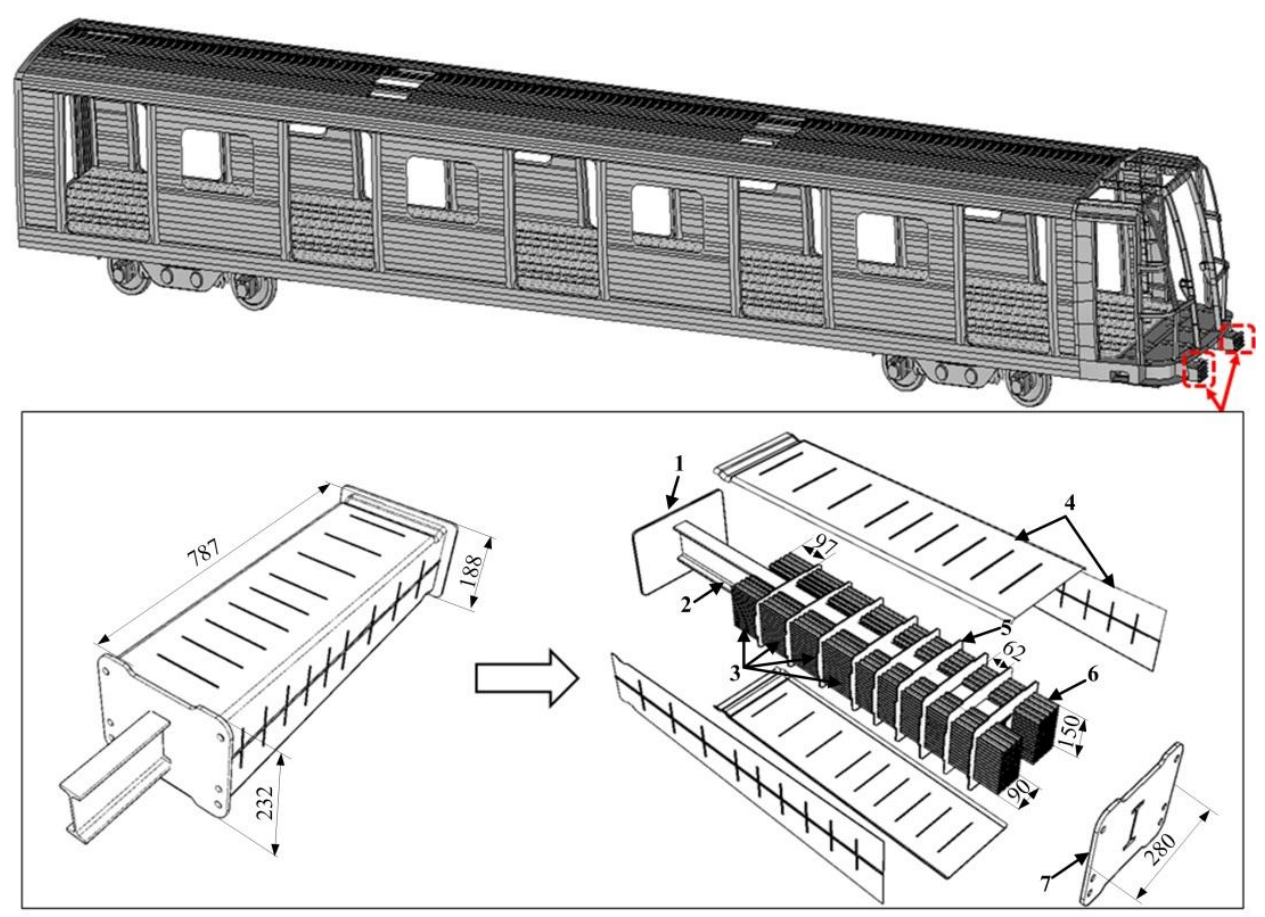

Fig. 1 The composite EAS and its components (1-front-end plate ; 2-guide; 3-A type aluminium honeycomb; 4-quadrate-tapered thin-walled tube; 5-diaphragm; 6-B type aluminium honeycomb;7-back-end plate) 


\subsubsection{Definition of the FEM}

The collision analysis model used for crashworthiness optimisation of the composite EAS was established in non-linear finite element software ANSYS/LS-DYNA, as shown in Fig. 2. The quadrate-tapered thin-walled tube is discretised by employing element type Shell 163 while Solid 164 is used to discretise the front-and back-end plates and the guide. The welding of the quadrate-tapered thin-walled tube, the diaphragms and front-and back-end plates is simulated by coupling nodes. To complete, effectively and accurately, the crashworthiness optimisation of the structure, the honeycomb core is defined by using the Type 126 honeycomb equivalent material with anisotropy (mechanical property) and its discretisation with element type, Solid 164 (Yao et al. 2018).

During the analysis process, one end of the composite EAS is fixed while the other end is compressed for $35 \mathrm{~ms}$ by using an ideal rigid wall at a uniform speed. The wall thickness $t_{1}$ of the quadrate-tapered thin-walled tube, the side length $l$ and thickness $t_{2}$ of unit cell of honeycomb structure are used as optimisation parameters. The crashworthiness behaviour of the EAS is evaluated by using various indexes including $S E A, F_{i p}, F_{a v g}$, and $C F E$.

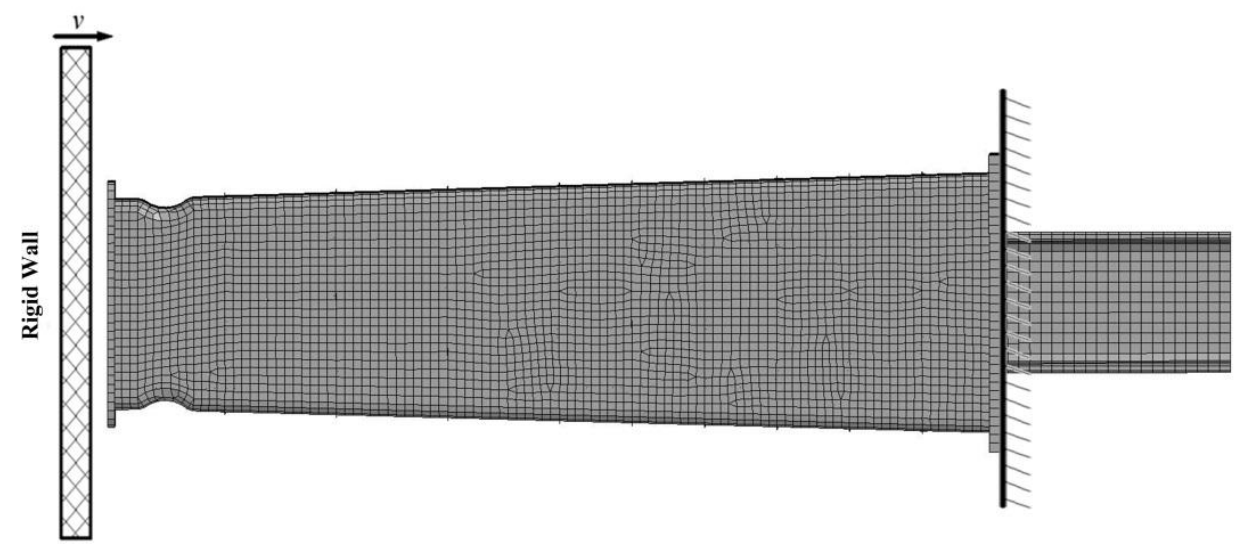

Fig. 2 The finite element model analysis conditions for optimisation

\subsubsection{Material model of the structure}

Considering the strain rate effect for a low strain rate condition, Cowper-Symonds models were chosen to model the steel structure (Hallquist 2006; Zhong 1993). The constitutive equation of the material can be described by Eq. (4):

$$
\sigma_{y}=\left[1+\left(\frac{\&}{C}\right)^{\frac{1}{p}}\right]\left(\sigma_{0}+\beta E_{p} \varepsilon_{e f f}^{p}\right)
$$


where $\sigma_{y}$ is the yield stress; $C$ and $P$ are the strain rate parameters for the Cowper-Symonds model; $\&$ is the strain rate; $\sigma_{0}$ represents the initial stress; $\varepsilon_{\text {eff }}^{P}$ is the equivalent plastic strain; $E_{P}$ is the plastic hardening modulus, $E_{P}=E_{\tan } E /\left(E-E_{\tan }\right) ; E$ is the Young's modulus; $E_{\tan }$ is the tangent modulus of plastic deformation; $\beta$ denotes the hardening parameters that varies between 0 and 1. According to the literature (Yao et al. 2018; Xie et al. 2018), on the basis of the material of energy-absorbing structure, the parameters in Table 1 are taken as the material parameters for the Q235 steel structure in this numerical crash analysis.

Table 1 Material parameters for the steel structure.

\begin{tabular}{ccccccccc}
\hline Material parameters & $\rho /\left(\mathrm{kg} \cdot \mathrm{m}^{-3}\right)$ & $v$ & $E / \mathrm{GPa}$ & $\beta$ & $\sigma_{0} / \mathrm{MPa}$ & $E_{\mathrm{tan}} / \mathrm{MPa}$ & $C / \mathrm{s}^{-1}$ & $P$ \\
\hline Numerical value & $7.85 \times 10^{3}$ & 0.30 & 210 & 1 & 235 & 763 & 40 & 5 \\
\hline
\end{tabular}

Fig. 3 shows a typical honeycomb core structure with its double thickness cell walls. Based on the literature (Wang et al. 2014; Xie and Zhou 2014; Yao et al. 2018; Xie et al. 2018), the thickness, width, and length of the honeycomb core are represented by $T, W$, and $L ; t_{2}$ is the thickness of the aluminium foil; $l$ and $h$ are side lengths of the unit cell; $\theta$ is the cell wall angle of unit cell; and when the cells are regular, $l=h$ and $\theta=30^{\circ}$. The size $t_{2} \times l \times h$ of unit cell of aluminium honeycomb in the composite EAS is $0.06 \mathrm{~mm} \times 2 \mathrm{~mm} \times 2 \mathrm{~mm}$.
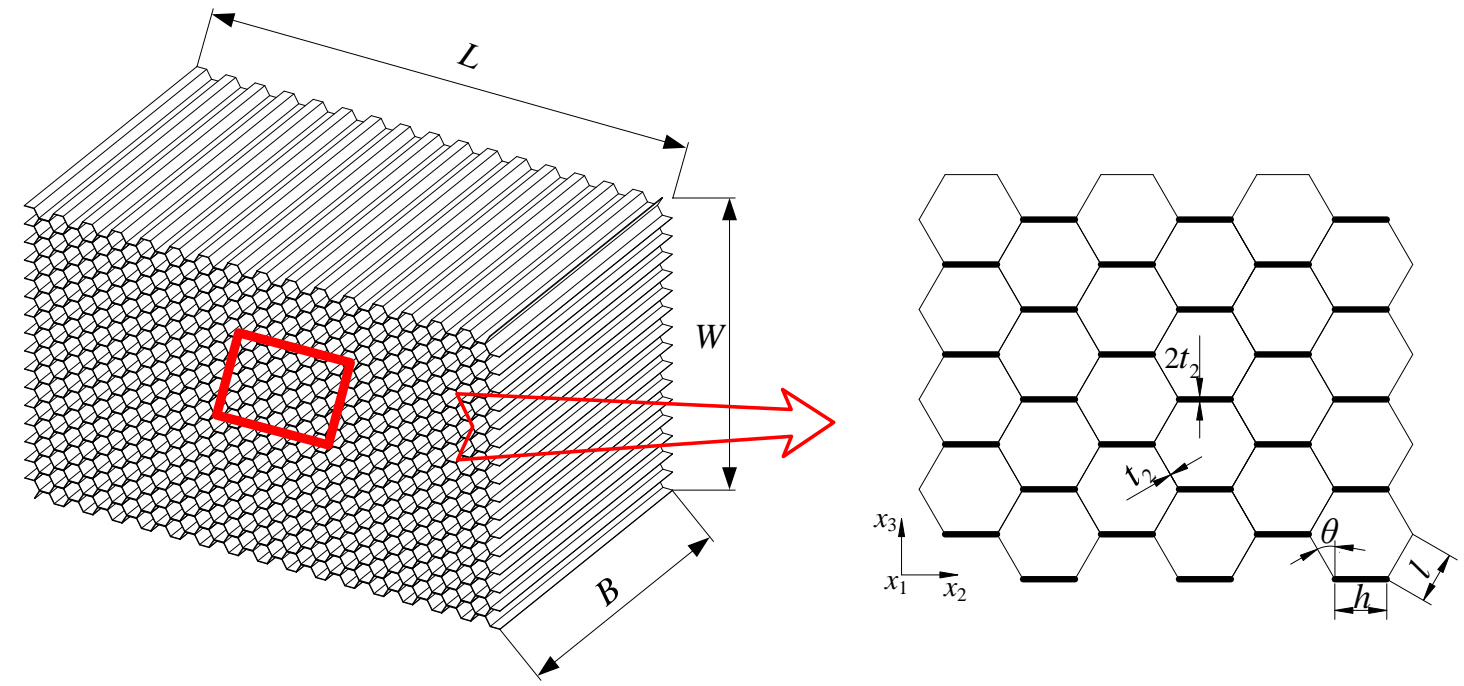

Fig. 3 Specification of honeycomb core of the composite EAS

In addition, the material model of the aluminium honeycomb of the composite EAS has been validated elsewhere (Xie and Zhou 2014; Yao et al. 2018; Xie et al. 2018) by the authors. 


\subsection{Validation of the numerical model}

To analyse the crash performance of the composite EAS and validate the accuracy of the FEM, the modelling results of the structure under dynamic loads were compared with the experimental data. The impact experiment was carried out on the impact experimental bench of Key Laboratory of Traffic Safety on Track (Central South University), Ministry of Education. The impact experimental bench was consisted of the rigid wall installing force sensors with high sensitivity and precision, the crash test trolley, standard tracks, the driving and braking systems, the control system, and the experimental data acquisition and test systems. The experimental and simulation model consisted of trolley and EAS as shown in Fig. 4, respectively. During the process of simulation, the boundary conditions were fully consistent with those applied to the experiment, and the same sampling frequency and filtering methods were used throughout.

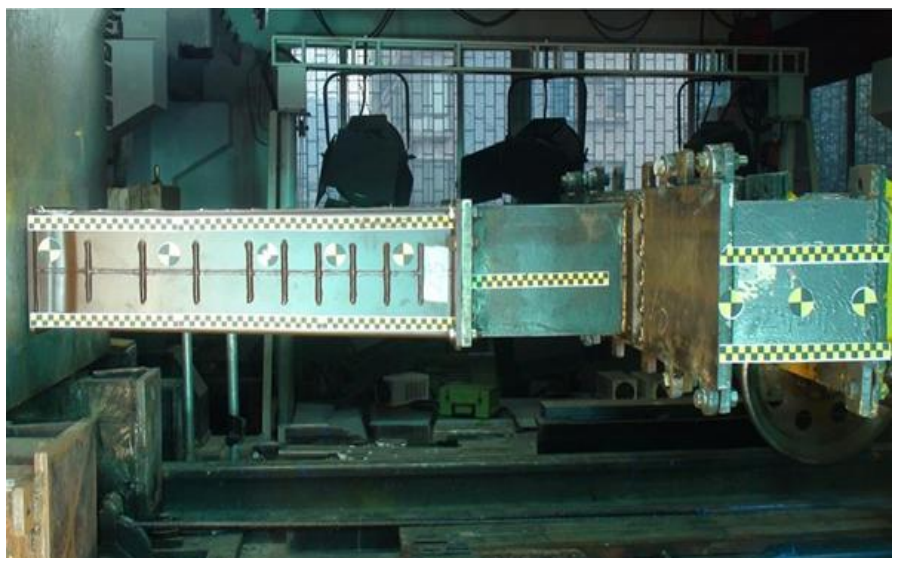

(a)

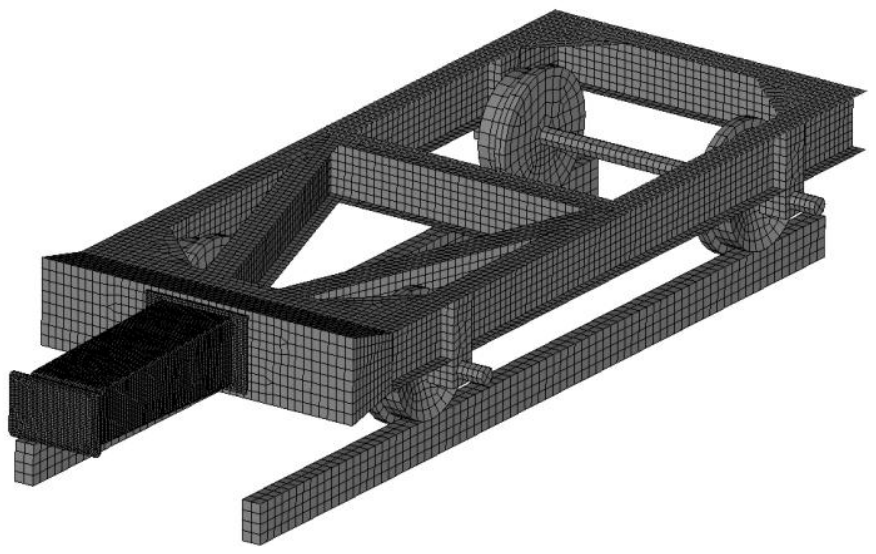

(b)

Fig. 4 (a) The experimental model of the trolley and EAS (b) FEM of the trolley and EAS

Many impact experiments and simulations have been carried out (Yao et al. 2018), which were not deemed to have been a priority in this research. Therefore, the deformation of the 
structures was only presented when the initial impact velocity of the trolley was $v_{0}=19.5 \mathrm{~m} \bullet \mathrm{s}^{-1}$ in this work. Fig. 5 shows the final deformation of the composite EAS from both the impact test and simulation, it can be seen that the simulation results showed similar trends to those found experimentally. Because the experimental conditions are more complex than those of the numerical simulation, the force-time curve, and the energy-displacement curve, in the experiment are not in good agreement with those of the simulation, as shown in Fig. 6; nevertheless, the trends therein are essentially consistent. All comparisons indicate that the simulation model can be applied to the next optimisation based on the verification thereof.

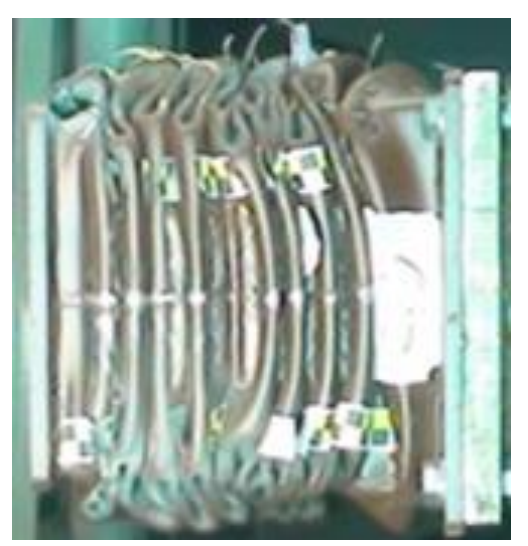

(a)

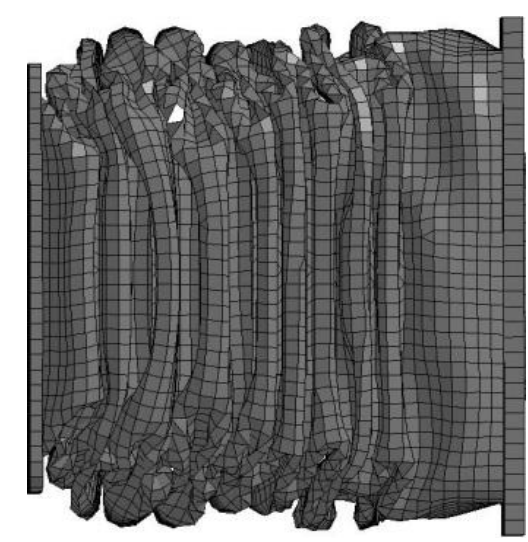

(b)

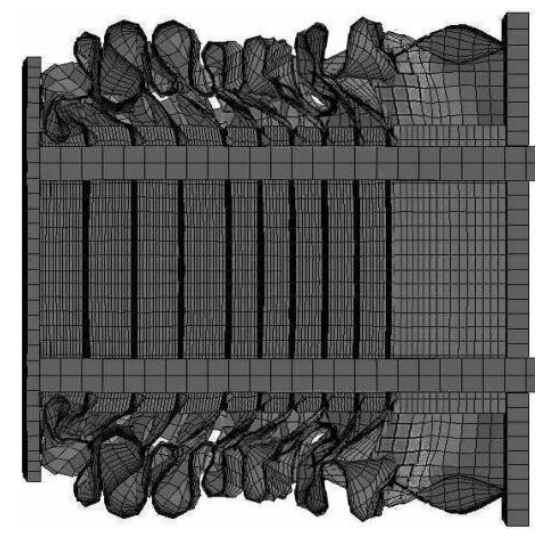

(c)

Fig. 5 Final deformation of the EAS through experiment and simulation: (a) Experimental result; (b)Simulation result; (c) The deformation of the inner honeycomb of the composite EAS for simulation 


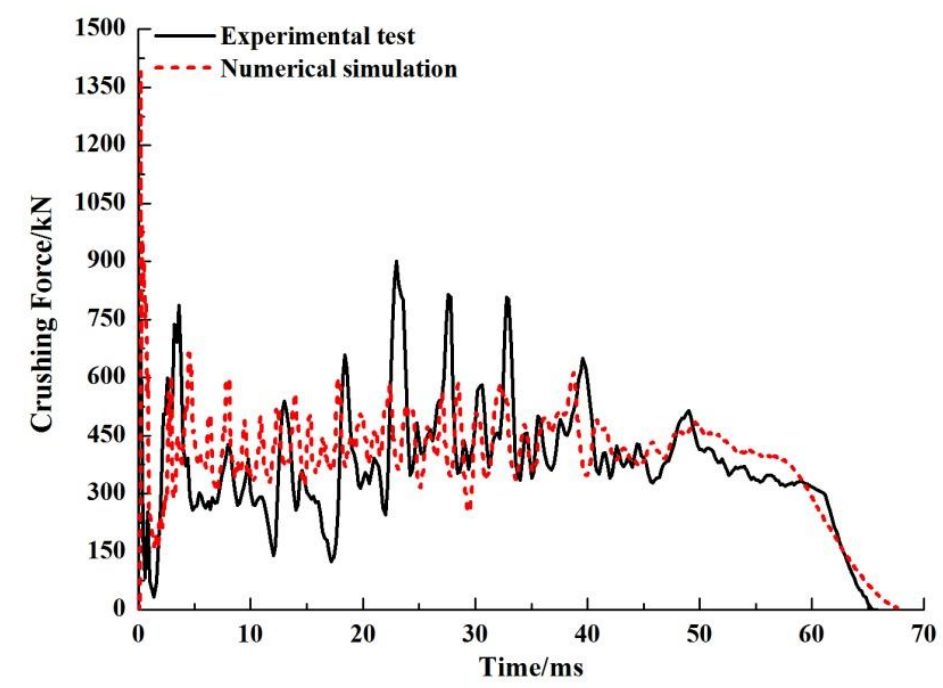

(a)

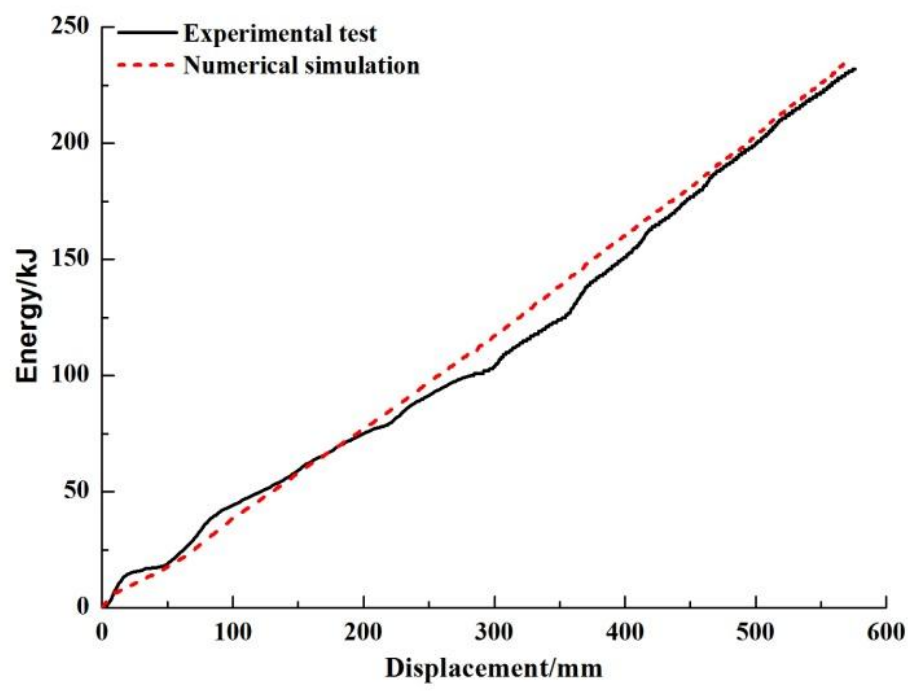

(b)

Fig. 6 Comparison of experimental and simulation results: (a) force-time curve; (b)

energy-displacement curve

\section{Optimisation with different surrogate models and HPSO}

\subsection{Optimisation formulation}

During the optimisation design of the composite EASs, it is expected that SEA of the structure is as large as possible within the effective compressive distance. This study focuses 
much more on the $S E A$ of the composite EAS than on other crashworthiness indexes, so the $C F E$, $F_{a v g}$ and $F_{i p}$ will be taken as extra constraints, and maximising the $S E A$ is taken as our major research objective. The wall thickness $t_{1}$ of the quadrate-tapered tube, the wall thickness $t_{2}$ of the unit cell of the honeycomb foil and the side length $l$ of the unit cell are taken as design variables, with the data ranges as follows: $1.5 \mathrm{~mm} \leq t_{1} \leq 3.5 \mathrm{~mm}, 1.0 \mathrm{~mm} \leq l \leq 5.0 \mathrm{~mm}$ and $0.04 \mathrm{~mm} \leq$ $t_{2} \leq 0.16 \mathrm{~mm}$, respectively.

According to the literature (Peng et al. 2015; Yao et al. 2018) and the requirement of GM/RT2100, the constraint of the optimisation is that the initial peak crushing force induced by collision is not more than $1,500 \mathrm{kN}$ and the deformation displacement should be less than $600 \mathrm{~mm}$ considering the load borne by the passengers in such subway vehicles. Additionally, the crashworthiness indexes including $C F E, F_{i p}$ and $F_{\text {avg }}$ are defined as the constraints to protect the passengers from severe damage during the collision process. To account for these design criteria, the optimisation problem can be formulated as a single-objective mathematical model as follows:

$$
\left\{\begin{array}{c}
\operatorname{SEax}\left(t_{1}, l, t_{2}\right) \\
\text { s.t. }\left\{\begin{array}{c}
S \leq 600 \mathrm{~mm} \\
C F E\left(t_{1}, l, t_{2}\right) \geq 0.30 \\
F_{i p}\left(t_{1}, l, t_{2}\right) \leq 1500 \mathrm{kN} \\
F_{\text {avg }}\left(t_{1}, l, t_{2}\right) \geq 360 \mathrm{kN} \\
1.5 \mathrm{~mm} \leq t_{1} \leq 3.5 \mathrm{~mm} \\
1.0 \mathrm{~mm} \leq l \leq 5.0 \mathrm{~mm} \\
0.04 \mathrm{~mm} \leq t_{2} \leq 0.16 \mathrm{~mm}
\end{array}\right.
\end{array}\right.
$$

\subsection{Design of experiment (DOE)}

Orthogonal experimental design (OED) can search optimal allocation and analysis information reflecting the comprehensive experimental conditions by conducting fewer experiments. Therefore, the study selected 25 training samples based on three-factor and five-level OED to fit (or interpolate) different surrogate models and chose 20 testing samples to validate the accuracy of each surrogate model. The spatial distributions of 25 training samples and 20 testing samples are displayed in Fig. 7. 


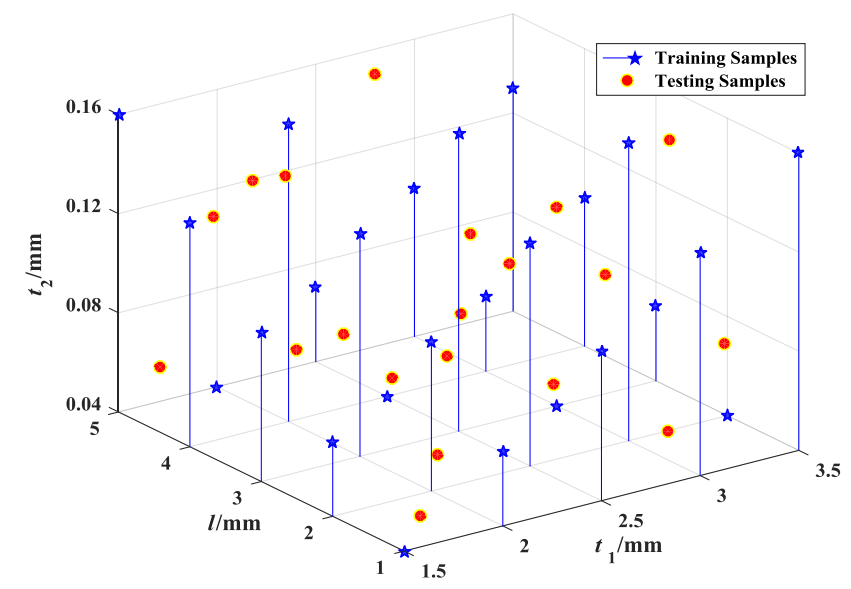

Fig. 7 Spatial distributions of training and testing samples

\subsection{The establishment of surrogate models}

To reduce the time required for finite element simulation and analysis, the surrogate model was employed in optimising the crashworthiness of the composite EAS. It is unclear which surrogate model is the most accurate one for predicting of crashworthiness indexes before the optimisation design. Therefore, a comparative investigation of different surrogate models to choose the most suitable one for subsequent optimization becomes even more necessary. In this study, the approximate functions of crashworthiness indexes on the design variables are obtained by using four surrogate models involving the polynomial response surface (PRS) model Xie and Zhou (2014), radial basis function (RBF) model (Sun et al. 2011; Zhao and Xue 2010; Sun et al. 2010; Esfahlani et al. 2013), Kriging model (Simpson TW 2015, Xie and Zhou 2014) and supported vector regression (SVR) model (Clarke et al. 2005, Zhu et al. 2012). The approximate functions and relevant parameters of the four models are shown in Table 2.

Table 2 Approximate and basic (correlation and kernel) functions of four types of surrogate models.

\begin{tabular}{ccc}
\hline Surrogate model & Approximate function & Basic(correlation, kernel) function \\
\hline PRS-3 & $a_{0}+\sum_{i=1}^{n} a_{i} x_{i}+\sum_{i=1}^{n} \sum_{j=1}^{n} b_{i j} x_{i} x_{j}+\sum_{i=1}^{n} \sum_{j=1}^{n} \sum_{k=1}^{n} b_{i k} x_{i} x_{j} x_{k}$ & Cubic polynomial functions \\
RBF & $\sum_{i=1}^{n} r_{i} \varphi\left(\left\|\mathbf{x}-\mathbf{x}_{\mathbf{i}}\right\|\right)$ & $\varphi\left(\left\|\mathbf{x}-\mathbf{x}_{\mathbf{i}}\right\|\right)=\sqrt{\left\|\mathbf{x}-\mathbf{x}_{\mathbf{i}}\right\|^{2}+c^{2}}$ \\
& $c=1.5$ \\
\hline
\end{tabular}


Kriging

$$
\mathbf{r}^{T}(\mathbf{x}) \mathbf{R}^{-1}(\mathbf{Y}-\mathbf{F} \hat{\boldsymbol{\beta}})+\mathbf{f}(\mathbf{x})^{T} \hat{\boldsymbol{\beta}}
$$

$$
R\left(x_{i}, x_{j}\right)=\prod_{k=1}^{n_{d v}} \exp \left(-\theta_{k}\left|x_{k}^{i}-x_{k}^{j}\right|^{2}\right)
$$

$0.1 \leq \theta_{k} \leq 30$

SVR

$$
\sum_{i=1}^{n}\left(a_{i}-a_{i}^{*}\right) k\left(\mathbf{x}_{\mathbf{i}} \cdot \mathbf{x}\right)+b
$$

$$
k\left(\mathbf{x}, \mathbf{x}^{\prime}\right)=\exp \left(-\frac{\left\|\mathbf{x}-\mathbf{x}^{\prime}\right\|^{2}}{2 \sigma^{2}}\right)
$$

$$
\sigma=2
$$

\subsection{Error evaluation criterion}

To evaluate the accuracy of the surrogate models, 20 testing samples are selected from the sample space, as shown in Fig. 7. The mean relative error (MRE) is used for measuring the local accuracy of the surrogate model while the root-mean-square error (RMSE) is used to measure its global precision. The lower the MRE and RMSE, the higher the accuracy of the models. RMSE and MRE between the FEA result $y_{i}$ and the approximation result based on the corresponding predicted $\hat{y}_{i}$ are calculated using Eqns (6), and (7), respectively:

$$
\begin{aligned}
& \text { RMSE }=\sqrt{\frac{\sum_{i=1}^{M}\left(y_{i}-\hat{y}_{i}\right)^{2}}{M}} \times 100 \% \\
& M R E=\frac{\sum_{i=1}^{M}\left|\left(\hat{y}_{i}-y_{i}\right) / y_{i}\right|}{M} \times 100 \%
\end{aligned}
$$

$R^{2}$, the coefficient of determination, is considered as another important index when evaluating the accuracy of models and it can be calculated as follows:

$$
R^{2}=1-\frac{S S E}{S S T}=1-\frac{\sum_{i=1}^{M}\left(y_{i}-\hat{y}_{i}\right)^{2}}{\sum_{i=1}^{M}\left(y_{i}-\bar{y}\right)^{2}}
$$

where, $M$ and $\bar{y}$ represent the number $(M=20)$ of the testing samples and the mean value for the simulation analysis, respectively.

\subsection{HPSO}

\subsubsection{The principle of the optimisation algorithm}

The linear decreasing inertia weight PSO (LDIW-PSO) with proper parameter setting (Arasomwan and Adewumi 2013) is introduced as a major part of hybrid particle swarm 
optimisation (HPSO) algorithm. With increasing iterations through the LDIW-PSO algorithm, the deep-search capacity of the algorithm gradually decreases. On the premise of failing to impair cooperation between particles, the explosion operation of the fireworks algorithm (FWA) (Tan and Zhu 2010) is introduced in which the individual extremum updated by the LDIW-PSO algorithm is taken as the explosion firework to strengthen the local search capacity and diversity of the algorithm. The explosion number and radius of each firework in the firework explosion operation depend on the values of fitness functions for all individual extremums. To adjust, self-adaptively, the explosion radius of the firework to adapt different decision variables and increase disturbance accuracy, the explosion update of the individual extremums and the number of fireworks generated by the explosion update are as displayed in Formulae (9) to (12). Additionally, to avoid premature convergence of the algorithm, the global extremum undergoes logistic mapping treatment (Yong et al. 2015) to help the HPSO algorithm jump over local optima.

$$
\begin{aligned}
& A^{l, t}=\hat{A} \cdot \frac{F\left(\text { pbest }^{l, t}\right)-F\left(\text { pbest }^{t}\right)^{\min }+\varepsilon}{\sum_{l=1}^{\text {Sizepop }}\left(F\left(\text { pbest }^{l, t}\right)-F\left(\text { pbest }^{t}\right)^{\min }\right)+\varepsilon} \\
& S^{l, t}=M \cdot \frac{F\left(\text { pbest }^{t}\right)^{\max }-F\left(\text { pbest }^{l, t}\right)+\varepsilon}{\sum_{l=1}^{S_{i z e p o p}}\left(F\left(\text { pbest }^{t}\right)^{\max }-F\left(\text { pbest }^{l, t}\right)\right)+\varepsilon} \\
& S^{l, t}=\left\{\begin{array}{l}
S^{\min }, \text { if } S^{l, t}<S^{\min } \\
S^{\max }, \text { if } S^{l, t}>S^{\max } \\
\text { round }\left(S^{l, t}\right), \text { otherwise }
\end{array} \quad S^{\min }=a \cdot M, S^{\max }=b \cdot M\right. \\
& \text { pbest }_{i}^{l, t, \alpha}=\text { pbest }_{i}^{l, t}+\operatorname{round}(\operatorname{rand}(0,1)) \cdot \omega^{t} \cdot A^{l, t} \cdot \operatorname{rands}(-1,1) \cdot\left(x s_{i}^{\text {max }}-x s_{i}{ }^{\text {min }}\right), \alpha \in\left\{1,2, S^{l, t}\right\}
\end{aligned}
$$

In the $t$ th iteration, pbest $t_{i}^{l, \alpha}$, pbest $t_{i}^{l, t}$, and $\omega^{t}$ refer to the $i$ th-dimensional location of the individual extremum of the particle $l$ in the $\alpha$ th explosion, the $i$ th-dimensional location of the individual extremum of the particle $l$, and inertia weight, respectively. Moreover, $A^{l, t}, x s_{i}^{\max }$ and $x s_{i}^{\min }$ represent the explosion radius of the individual extremum of the particle $l$, the maximum and minimum locations of the particle in the $i$ th-dimension, respectively. $S^{l, t}$, Sizepop and $\hat{A}$ refer to the explosion number of individual extremum of particle $l$, population size, and the constant of explosion radius of fireworks, respectively. $M, F\left(\text { pbest }^{t}\right)^{\max }$ and $F\left(\text { pbest }^{t}\right)^{\min }$ represent the constant of explosion number, and the maximum and minimum fitness values of 
individual extremums, respectively. Additionally, round $(\cdot)$ means rounding and $\operatorname{rands}(-1,1)$

refers to a random value on $[-1,1]$ while $\varepsilon$ represents an infinitesimal real number. $S^{\max }$ and $S^{\min }$ refer to upper-and lower-limit parameters for controlling the number of explosion; a and b denote the constant parameters controlling fireworks' bounds.

\subsubsection{Implementation of the proposed algorithm}

Step 1: Initialisation;

1.1 Setting parameters of HPSO algorithm;

1.2 The speed and location of the particle are randomly initialised to acquire $x s^{t}$ and $v s^{t}$

1.3 The fitness value $F\left(x s^{t}\right)$ of the particle is calculated and the individual extremum pbest ${ }^{t}=x s^{t}$. Afterwards, the global extremum gbest ${ }^{t}$ is updated based on pbest ${ }^{t}$.

Step 2: Set $t=t+1$, the speed $v s^{t}$ and location $x s^{t}$ of the particles are updated, as shown in Formulae (13), (14), (15), and (16).

Step 3: Whether, or not, the individual extremum is updated is judged by comparing the fitness function values of pbest $^{t-1}$ and updated particle $x s^{t}$.

Step 4: According to Formulae (9), (10), (11), and (12), the pbest ${ }^{t}$ is taken as a firework to undergo explosion updating. On this basis, the fitness value is calculated to update pbest ${ }^{t}$.

Step 5: By comparing the fitness values of gbest $^{t-1}$ and pbest ${ }^{t}$ updated in Step 4, gbest $^{t}$ can be updated.

Step 6: According to Formulae (17) and (18), the fitness value of the $g b e s t^{t}$ in Step 5 is subjected to chaotic mapping treatment, and then update $g_{b e s t} t^{t}$ again.

Step 7: If $t>T$, the HPSO algorithm ends to output the globally optimal solution. Otherwise, return to Step 2.

$$
\begin{gathered}
\left\{\begin{array}{l}
v s s_{i}^{l, t}=\omega^{t-1} \cdot v s_{i}^{l, t-1}+c_{1} \cdot \text { rand } \cdot\left(\text { pbest } t_{i}^{l, t-1}-x s_{i}^{l, t-1}\right)+c_{2} \cdot \text { rand } \cdot\left(\text { gbest }_{i}^{t-1}-x s_{i}^{l, t-1}\right) \\
x s s_{i}^{l, t}=x s_{i}^{l, t-1}+v s_{i}^{l, t}
\end{array}\right. \\
\omega^{t-1}=\omega^{\max }-\frac{\left(\omega^{\max }-\omega^{\min }\right) \cdot(t-1)}{T} \\
v s_{i}^{l, t}=\left\{\begin{array}{l}
v s_{i}^{\text {max }}, \text { if } v s_{i}^{l, t}>v s_{i}^{\text {max }} \\
v s_{i}^{\text {min }}, \text { if } v s_{i}^{l, t}<v s_{i}^{\text {min }}
\end{array}\right.
\end{gathered}
$$




$$
\begin{gathered}
x s_{i}^{l, t}=\left\{\begin{array}{l}
x s_{i}^{\text {max }}, \text { if } x s_{i}^{l, t}>x s_{i}^{\text {max }} \\
x s_{i}^{\text {min }}, \text { if } x s_{i}^{l, t}<x s_{i}^{\text {min }}
\end{array}\right. \\
x c_{i}^{k+1}=\mu \cdot x c_{i}^{k} \cdot\left(1-x c_{i}^{k}\right), k=\{0,1,2, \mathrm{~L}, N-1\} \\
x c_{i}^{k}=\frac{\text { gbest }_{i}^{t}-x s_{i}^{\text {min }}}{x s_{i}^{\text {max }}-x s_{i}^{\text {min }}}
\end{gathered}
$$

In the $t$ th iteration, $v s_{i}^{l, t}$ and $x s_{i}^{l, t}$ denote the speed and location of particle $l$ in the $i$ th-dimension, respectively; $c_{1}$ and $c_{2}$ mean acceleration coefficients; $T, \omega^{\max }$, and $\omega^{\min }$ represent the maximum number of iterations, and maximum and minimum inertia coefficients, respectively, and gbest $_{i}^{t}$ denotes the location of the global extremum in the $i$ th dimension. Moreover, $v s_{i}^{\max }$ and $v s_{i}^{\min }$ separately refer to the maximum and minimum speeds of the particle in the $i$ th dimension. Moreover, $\mu, x c_{i}^{k}$, and $N$ represent the control parameter, the chaotic variable in the $i$ th dimension acquired in the $k$ th mapping and the maximum number of chaotic mapping operation, respectively.

Fig. 8 shows the detailed optimisation process by employing HPSO for the composite EAS. 


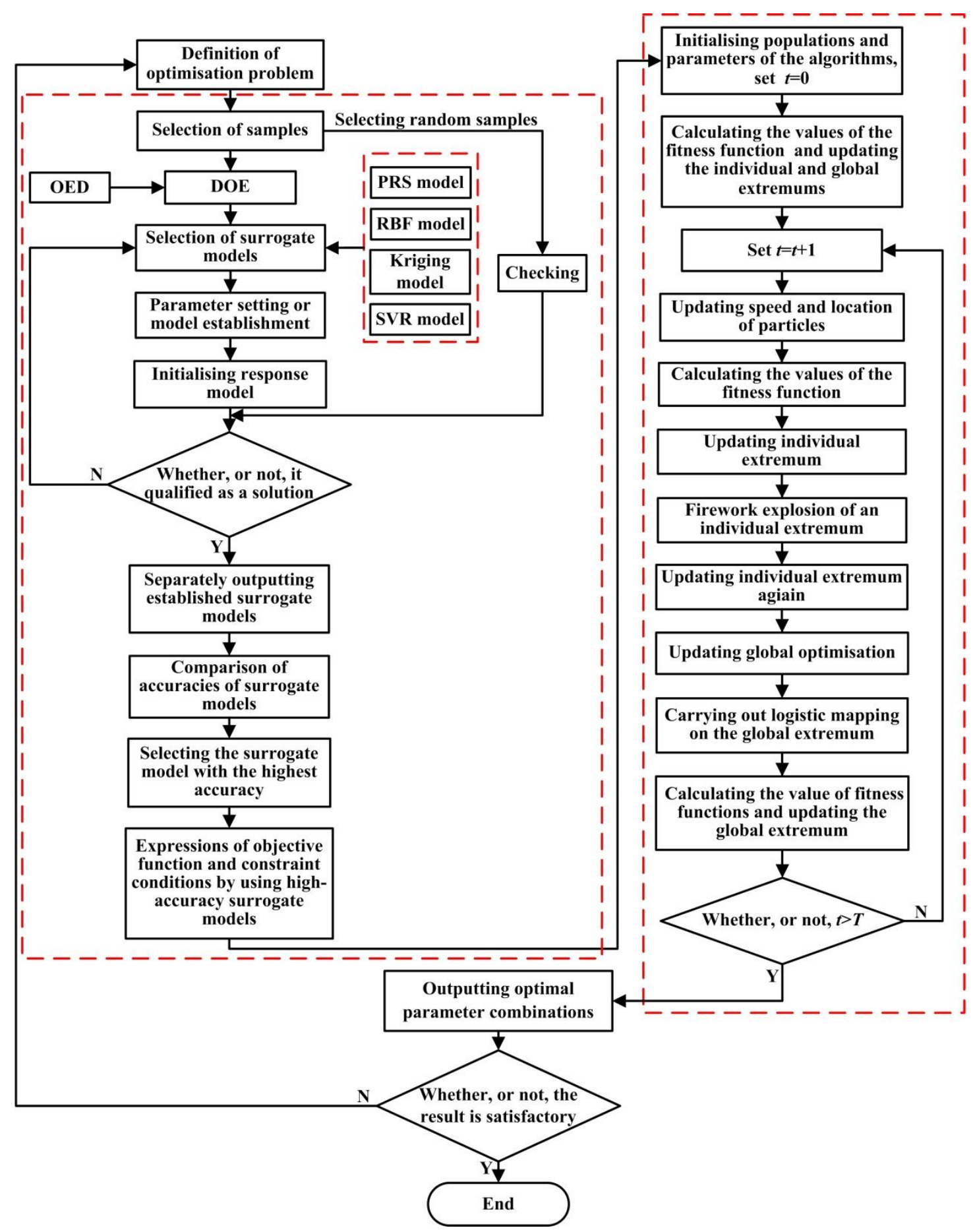

Fig.8 The optimisation process of HPSO algorithm for the composite EAS

\subsubsection{Performance testing}

The performance of the HPSO algorithm was tested by a typical engineering optimisation problem, and then the optimised results were compared with those of the algorithms in the existing literature. This problem involves three variables (including mean coil diameter $x_{1}$, wire diameter $x_{2}$, and the number of active coils $x_{3}$ ) and four non-linear constraints, as shown in Fig. 9. 


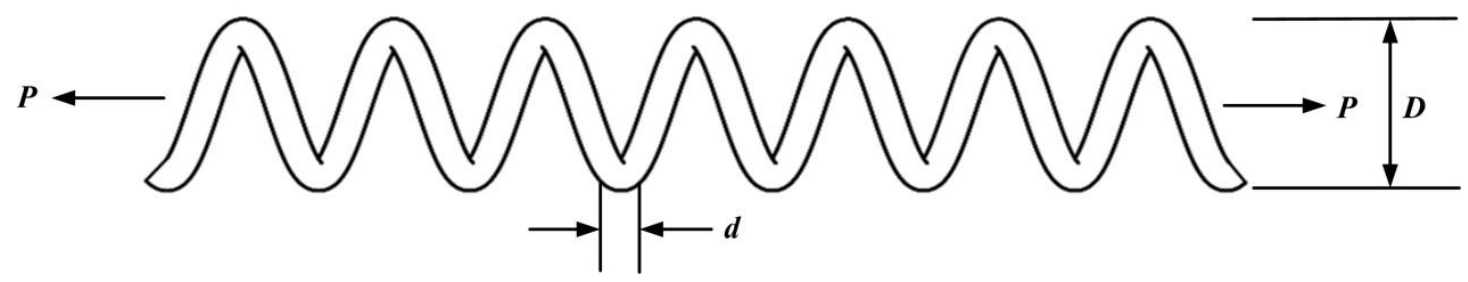

Fig. 9 Optimised design variables concerning tension/compression spring

The mathematical model of the problem is given by Formula (19):

$$
\left\{\begin{array}{l}
\min f(x)=\left(x_{3}+2\right) x_{2} x_{1}^{2} \\
\text { s.t. }\left\{\begin{array}{l}
\mathrm{F}_{1}(x)=1-\frac{x_{2}^{3} x_{3}}{71785 x_{1}^{4}} \leq 0 \\
\mathrm{~F}_{2}(x)=\frac{4 x_{2}^{2}-x_{1} x_{2}}{12566\left(x_{2} x_{1}^{3}-x_{1}^{4}\right)}+\frac{1}{5108 x_{1}^{2}}-1 \leq 0 \\
\mathrm{~F}_{3}(x)=1-\frac{140.45 x_{1}}{x_{2}^{2} x_{3}} \leq 0 \\
\mathrm{~F}_{4}(x)=\frac{x_{2}+x_{1}}{1.5}-1 \leq 0
\end{array}\right.
\end{array}\right.
$$

The data ranges of design variables of the model are displayed as follows: $0.05 \leq x_{1} \leq$ $2,0.25 \leq x_{2} \leq 1.3$ and $2 \leq x_{3} \leq 15$. The parameters of the HPSO algorithm are set as follows: sizepop $=60, T=500, c_{1}=c_{2}=1.9 ; \hat{A}=1, M=100, \varepsilon=0.0000001, N=10$ and $\mu=4$. The algorithm independently works 30 times. To compare the performance between the HPSO and other algorithms in a fair manner, the efficiency of the algorithm is reflected by the number of function evaluations Yildiz (2009), as shown in Table 3. By employing the HPSO algorithm, the optimal solution can be found after conducting 30,000 function evaluations. It can be seen from the evaluation indexes of optimisation results that the HPSO is superior to other algorithms. By checking the results of each evaluation, it can be speculated that the algorithm presents stable optimisation performance due to the very low standard deviation (1.397E-6). Therefore, it is feasible to apply the HPSO algorithm into subsequent crashworthiness optimisation of the composite EAS.

Table 3 The optimised results of the tension/compression spring based on seven algorithms.

\begin{tabular}{cccccc}
\hline Different Algorithms & Best & Mean & Worst & Standard deviation & Function evaluations \\
\hline HPSO & 0.01266523 & 0.012666 & 0.012671 & $1.397 \mathrm{E}-6$ & 30,000 \\
Yong et al. (2015) & 0.01266602 & 0.012763 & 0.012856 & $3.52 \mathrm{E}-5$ & 35,000 \\
\hline
\end{tabular}




\begin{tabular}{cccccc}
\hline Arasomwan and Adewumi (2013) & 0.01266526 & 0.012708 & 0.012797 & $7.07 \mathrm{E}-6$ & 35,000 \\
Yildiz(2009) & 0.01266527 & 0.012673 & 0.012708 & $6.24 \mathrm{E}-6$ & 30,000 \\
Mahdavi et al. (2007) & 0.0126706 & 0.012735 & 0.012832 & $3.05 \mathrm{E}-5$ & 30,000 \\
Huang et al. (2007) & 0.0126747 & 0.012730 & 0.012924 & $5.20 \mathrm{E}-5$ & 204,800 \\
Coello and Montes (2002) & 0.01268100 & 0.012742 & 0.012973 & $5.90 \mathrm{E}-5$ & 80,000 \\
\hline
\end{tabular}

Table 4 A comparison of the optimised results for the tension/compression spring by using seven algorithms.

\begin{tabular}{cccccccc}
\hline $\begin{array}{c}\text { Constrain } \\
\text { ed } \\
\text { variables }\end{array}$ & HPSO & $\begin{array}{c}\text { Yong et al. } \\
(2015)\end{array}$ & $\begin{array}{c}\text { Arasomwan } \\
\text { and Adewumi } \\
(2013)\end{array}$ & Yildiz(2009) & $\begin{array}{c}\text { Mahdavi et } \\
\text { al. }(2007)\end{array}$ & $\begin{array}{c}\text { Huang et al. } \\
(2007)\end{array}$ & $\begin{array}{c}\text { Coello and } \\
\text { Montes } \\
(2002)\end{array}$ \\
\hline$x_{1}(d)$ & 0.05167724 & 0.05148182 & 0.051725645 & 0.0516904023 & 0.05115438 & 0.051728 \\
$x_{2}(D)$ & 0.3564334 & 0.35175268 & 0.3575984 & 0.3567500 & 0.34987116 & 0.357644 & 0.051989 \\
$x_{3}(p)$ & 11.3056574 & 11.58610148 & 11.2375167 & 11.2871200 & 12.0764321 & 11.244543 \\
$F_{1}(x)$ & $-5.19 \mathrm{E}-8$ & $-4.43 \mathrm{E}-8$ & $-9.11 \mathrm{E}-13$ & -0.0000058368 & 0.000000 & -0.000845 \\
$F_{2}(x)$ & $-3.73 \mathrm{E}-10$ & $-4.65 \mathrm{E}-8$ & $-3.16 \mathrm{E}-13$ & -0.0000010045 & -0.000007 & $-1.26 \mathrm{E}-5$ & -0.000013 \\
$F_{3}(x)$ & -4.053223373 & -4.0438661 & -4.055521597 & -4.0537944322 & -4.0278401 & -4.051300 \\
$F_{4}(x)$ & -0.727926260 & -0.73117699 & -0.727117248 & -0.7277134115 & -0.7365723 & -0.727090021 \\
$f(x)$ & 0.01266523 & 0.01266602 & 0.01266526 & 0.01266527 & 0.0126706 & -4.061338 \\
\hline
\end{tabular}

\section{Results and discussion}

\subsection{Error analysis of surrogate models}

To compare the accuracy of four surrogate models (PSR, RBF, Kriging, and SVR), 20 testing samples were randomly selected from the sample space, as illustrated in Fig. 7. According to Formulae (6) to (8) for error evaluation in Section 3.4, the accuracy evaluation results of four models are obtained, as shown in Fig. 10 and Table 5. 


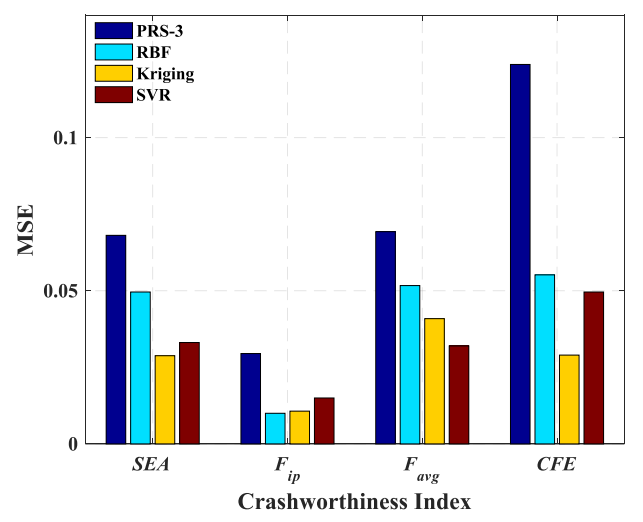

(a)

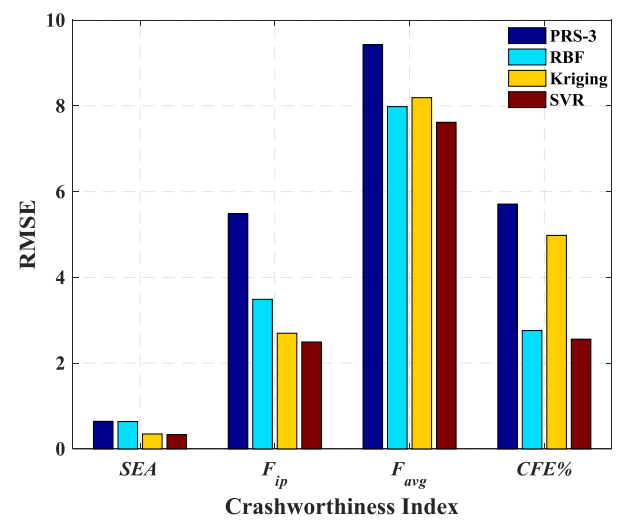

(b)

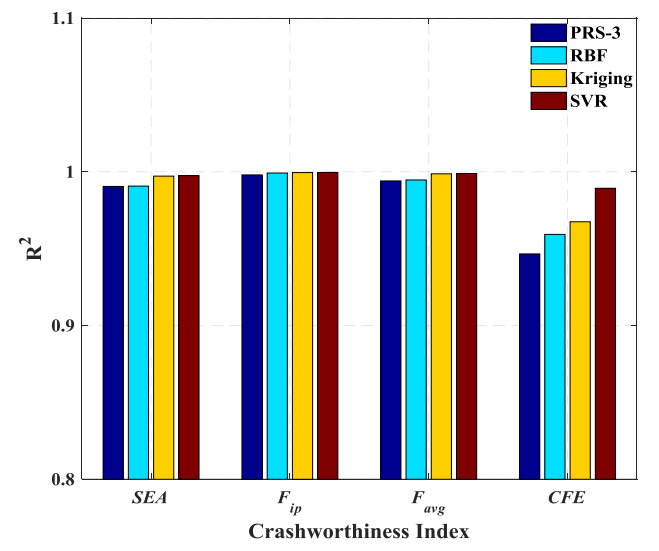

(c)

Fig. 10 A comparison of errors of four surrogate models

Table 5 Evaluation results of errors of four surrogate models.

\begin{tabular}{cccccc}
\hline Objective & Error index & PRS-3 & RBF & Kriging & SVR \\
\hline \multirow{2}{*}{ SEA } & RMSE & 0.6436 & 0.6375 & 0.3488 & 0.3310 \\
& $M R E$ & 0.0681 & 0.0496 & 0.0288 & 0.0331 \\
& $R^{2}$ & 0.9905 & 0.9907 & 0.9972 & 0.9975 \\
\hline \multirow{2}{*}{$F_{\text {ip }}$} & RMSE & 5.4832 & 3.4881 & 2.6978 & 2.4938 \\
& $M R E$ & 0.0295 & 0.0100 & 0.0107 & 0.0150 \\
\hline \multirow{2}{*}{$F_{\text {avg }}$} & $R^{2}$ & 0.9980 & 0.9992 & 0.9995 & 0.9996 \\
\hline \multirow{2}{*}{$C F E$} & RMSE & 9.4244 & 7.9828 & 8.1916 & 7.6176 \\
\hline
\end{tabular}




\begin{tabular}{ccccc}
\hline MRE & 0.1239 & 0.0552 & 0.0290 & 0.0296 \\
$R^{2}$ & 0.9466 & 0.9593 & 0.9675 & 0.9893 \\
\hline
\end{tabular}

As shown in Table 5 and Fig. 10, the RMSE and MRE of the PRS-3 model for predicting crashworthiness indexes are all larger than those of the other three models. The values of $R^{2}$ of RBF and Kriging models for predicting CFE are relatively low. However, the crashworthiness indexes of the composite EAS predicted by the SVR model are both relatively optimal.

Fig. 11 shows the different four-dimensional response model of the SEA on design variables under constraints. It can be seen from the figure that, except for the PSR-3 model, the other three response models are similar, showing approximately the same monotonicity: the objective function monotonically increases with growing thicknesses of quadrate-tapered tube and unit cell of aluminium honeycomb while monotonically decreases with increasing side length of the unit cell of the aluminium honeycomb. The overall consistency of the four models basically conforms to $R^{2}$ values of the SEA in Table 5. Additionally, it can be concluded that compared with the thickness $t_{2}$ of the unit cell of the aluminium honeycomb, the side length $l$ of the unit cell of the aluminium honeycomb and the thickness $t_{1}$ of the quadrate-tapered tube have a more significant effect on the SEA of the composite EAS.

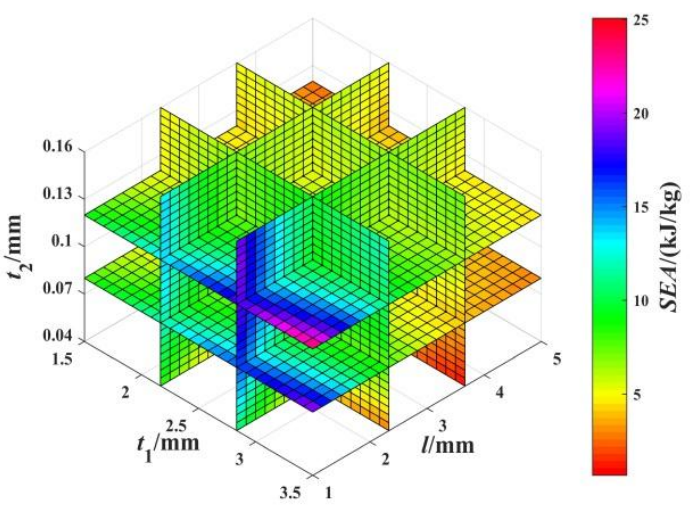

(a) PRS-3 model

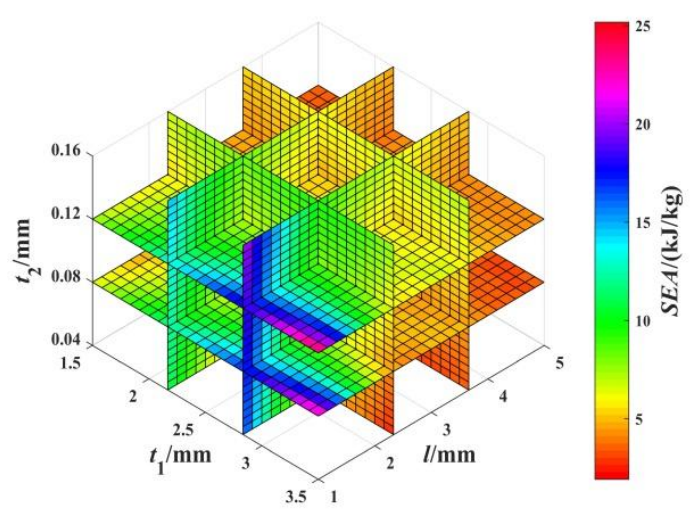

(b) RBF model 


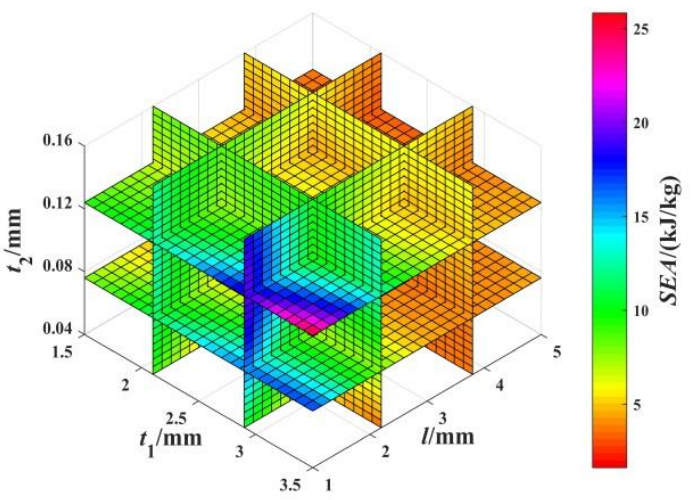

(c) Kriging model

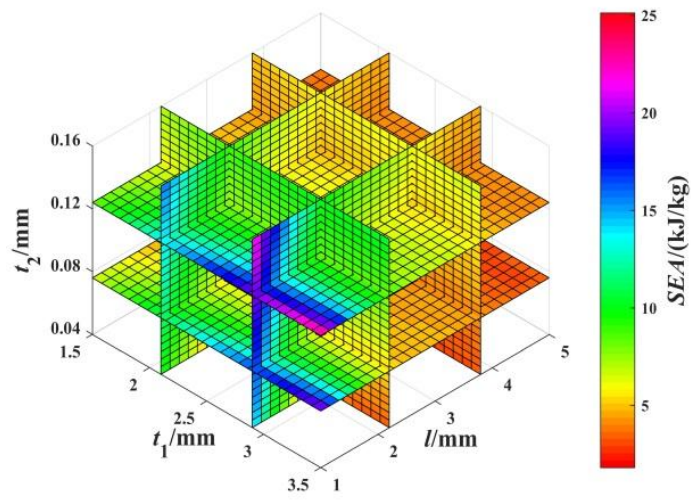

(d) SVR model

Fig. 11 Four response models of SEA under the effect of influence factors: (a) PRS-3 model (b)

RBF model (c) Kriging model (d) SVR model

According to the above analysis, the four surrogate models show approximately similar trends in predicting SEA. However, there is the highest accuracy in predicting four crashworthiness indexes of the composite EAS by using the SVR model, therefore the SVR model is employed as the surrogate mode for subsequent optimisation. The expressions for crashworthiness indexes were acquired by applying the support vector regression method, as shown in Formulae 20 to 23 in the Appendix.

\subsection{Optimisation and validation}

The HPSO algorithm is proposed based on the LDIW-PSO by integrating the explosion operator of the FWA. To acquire the optimal crashworthiness design of the composite EAS for subway vehicles, the single-objective mathematical model in Section 3.1 is optimised by using FWA, LDIW-PSO and the HPSO algorithms proposed in Section 3.5, respectively. The algorithms are separately run 30 times independently, and the parameters used by the algorithms for the optimisation are as follows: a) Number of fireworks or particles: 100; b) Maximum number of iterations: 300; c) Number of function evaluations: 30,000.

The dimensional parameters of the composite EAS of subway vehicles in terms of each optimal SEA and the optimal SEA obtained using the algorithms are listed in Table 6.

Table 6 Optimisation results of the composite EAS using different algorithms.

\begin{tabular}{cccccc}
\hline & Iterations & $t_{1} / \mathrm{mm}$ & $l / \mathrm{mm}$ & $t_{2} / \mathrm{mm}$ & $S E A /(\mathrm{kJ} / \mathrm{kg})$ \\
\hline FWA & 265 & 2.7177 & 1.0981 & 0.1569 & 19.0458 \\
\hline
\end{tabular}




\begin{tabular}{cccccc}
\hline LDIW-PSO & 187 & 2.7660 & 1.0000 & 0.1589 & 20.7081 \\
HPSO & 86 & 2.7720 & 1.0000 & 0.1600 & 20.8177 \\
\hline
\end{tabular}

Figure 12 (a) shows the converging curve for the SEA of the composite EAS optimised by the algorithms. It can be concluded that the optimal $S E A(20.8177 \mathrm{~kJ} / \mathrm{kg})$ was acquired by 86 iterations of the HPSO; applying LDIW-PSO, the optimal value of the structural SEA $(20.7081 \mathrm{~kJ} / \mathrm{kg})$ was obtained after 187 iterations and the optimal value of $19.0458 \mathrm{~kJ} / \mathrm{kg}$, as acquired by FWA reached optimal in 265 iterations. Figure 12(b) shows the boxplot (Tsai et al. 2010), which can graphically illustrate groups of data through their summaries including the smallest observation, upper quartile, median, lower quartile, the largest observation and indicate which observation might be an outlier. The closer the five-number summaries and outliers, the better the stability and convergence of the algorithm. It can intuitively be found that the stability and convergence of the FWA are inferiority to the HPSO and LDIW-PSO algorithms, and the optimised result of the LDIW-PSO is more uncertain than the HPSO due to the two extreme outliers. Obviously, the proposed HPSO performs the best and has the ability to find optimal solutions compared with other related methods (FWA and LDIW-PSO) for this optimisation problem.

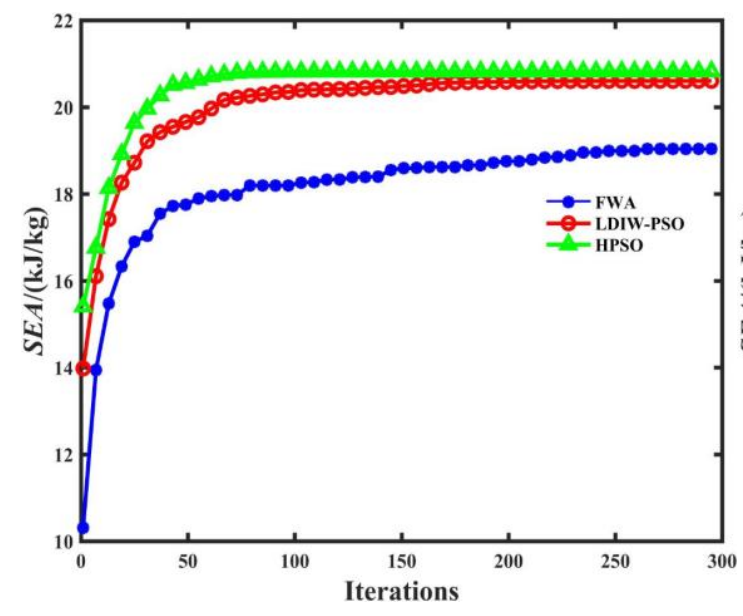

(a)

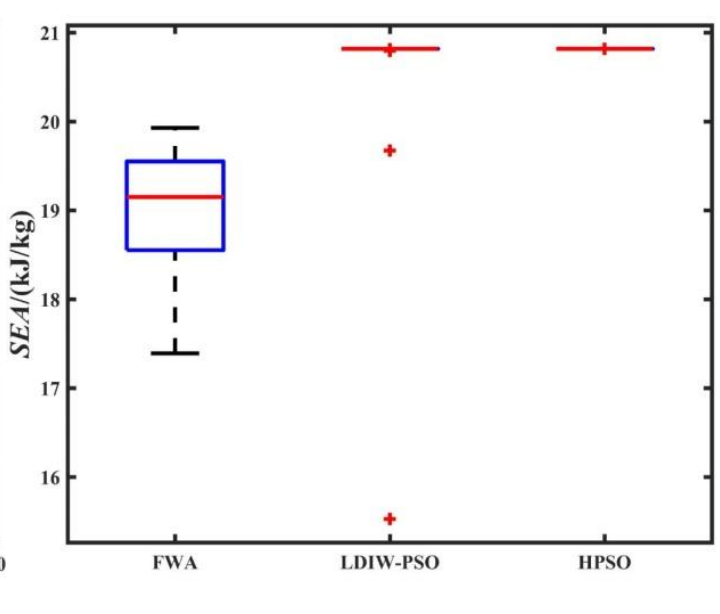

(b)

Fig.12 (a)The convergence curves for the metrics of the SEA optimised by FWA, LDIW-PSO and HPSO algorithms (b) Boxplot for the metric of the structural SEA

A comparative analysis of the results optimised by using the three algorithms presents that the SEA by using the HPSO is optimal. Fig. 13 shows the optimisation results in which the red 
arrow refers to the trend in motion of the optimisation of particles while a black particle denotes the optimum solution.

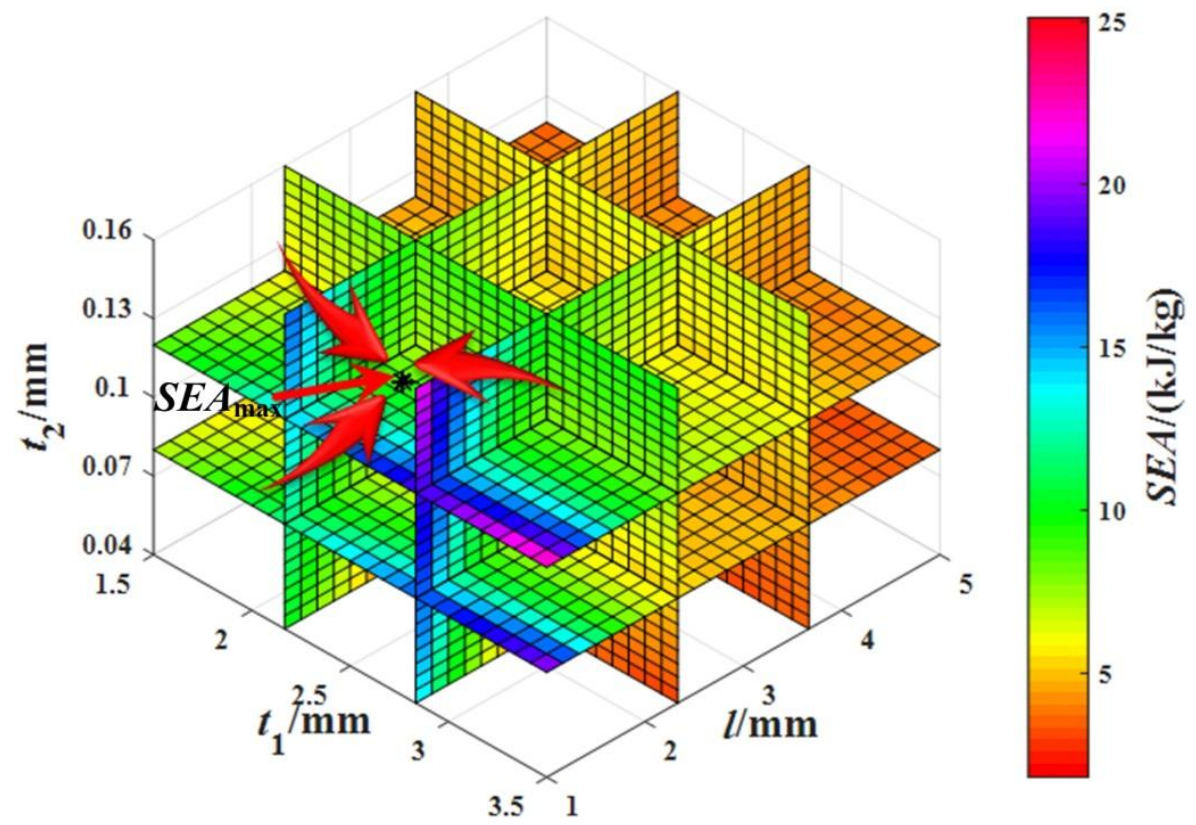

Fig. 13 The optimisation result obtained based on the HPSO algorithm

To verify the optimisation result, Table 7 compares the optimisation result of SVR model and finite element analysis (FEA) result. It can be concluded that there is a relatively low discrepancy between the two results, which validates the optimisation result obtained by the HPSO algorithm.

Table 7 Verification of optimal solution of the composite EAS based on FEA.

\begin{tabular}{ccc}
\hline & $S E A /(\mathrm{kJ} / \mathrm{kg})$ & $F_{i p} / \mathrm{kN}$ \\
\hline FEA & 20.8177 & 1499.5343 \\
Relative error \% & 20.4271 & 1486.1653 \\
& 1.9122 & 0.8996 \\
\hline
\end{tabular}

Table 8 lists the results of optimal, and initial, designs: it can be found that the SEA and CFE of the optimised structure increase by 1.6514 and 1.1379 times, respectively, while the compression displacement decreases by $46.88 \%$. Both the SEA and CFE of the composite EAS obtained by using optimal parameter combinations are both significantly improved, which indicates that the utilisation rate of the structure to materials increases. Although the aluminium honeycomb of the optimised EAS becomes dense, the quality of the overall structure shows no substantial increase. 
Table 8 A comparison between results of initial, and optimal, designs.

\begin{tabular}{ccccc}
\hline Categories & $S E A /(\mathrm{kJ} / \mathrm{kg})$ & $F_{i p} / \mathrm{kN}$ & Displacement $/ \mathrm{mm}$ & $C F E$ \\
\hline Initial design & 8.0813 & 1390 & 576.09 & 0.29 \\
Optimal design & 21.4271 & 1486.1653 & 305.99 & 0.62 \\
Optimized percentage (\%) & 165.14 & 6.92 & -46.88 & 113.79 \\
\hline
\end{tabular}

The SEA of the composite EAS, through optimal design, increases significantly compared with that under initial design conditions while the initial peak crushing force rises by a mere $6.92 \%$. The main reason is that the inducement groove with $40 \mathrm{~mm}$ radius in the front end of the composite EAS does not change before or after the optimisation. The inducement groove reduces the initial peak crushing force of the structure and also effectively avoids secondary collision damage to passengers.

\section{Conclusions}

(1) A composite EAS installed on the front-end of the underframe of a subway vehicle was designed. The structural FEM was simulated in LS-DYNA, and was then efficiently validated by dynamic impact tests. Based on the verified FEM, response models, representing the relationship between design variables and crashworthiness indexes, were separately constructed using OED and approximate alternative methods (PRS-3, Kriging, RBF, and SVR). By analysing the comprehensive error evaluation criterion, the prediction accuracy of the SVR model for crashworthiness indexes of the composite EAS is higher than that of other surrogate models in this study.

(2) Considering the complexity of the mathematic formulae of the composite EAS and the shortcomings inherent to LDWI-PSO during the optimisation process, a HPSO algorithm was proposed. By comparing the optimised results of the mathematical model of the tension/compression spring obtained by employing the HPSO and the algorithms as published elsewhere (Yong et al. 2015;Arasomwan and Adewumi 2013; Yildiz AR 2009; Mahdavi et al. 2007; Huang et al. 2007; Coello and Montes 2002), it can be speculated that the HPSO algorithm only requires 30,000 function evaluations to find the best-known solution of 0.01266523 which is superior to the optimised results published elsewhere, and the HPSO algorithm offers rapid convergence and high-optimising accuracy. 
(3) Through analysing the converging curves of the SEA obtained by using the algorithms including FWA, LDIW-PSO and HPSO, it is found that the HPSO algorithm can reach the optimal SEA (20.8177 kJ/kg) after a mere 86 iterations, which shows that the proposed HPSO performs better than all algorithms tested. In addition, it can be seen from the boxplot that the five-number summaries and outliers of the boxplot for the HPSO algorithm are the closest, which also shows that the HPSO has the best convergence and stability compared with FWA and LDIW-PSO algorithm for optimising the composite EAS.

(4) The mathematical model in Section 3.1 was optimised by employing the HPSO algorithm. The optimal configuration for the composite EAS is the thickness of quadrate-tapered thin-walled tube of $2.7720 \mathrm{~mm}$, the side length of the unit cell of the honeycomb of $1.0000 \mathrm{~mm}$ and the wall thickness of the unit cell of $0.1600 \mathrm{~mm}$. The $S E A$ of $20.4271 \mathrm{~kJ} / \mathrm{kg}$ can be obtained by using the FEM based on the optimal parameter combination. Compared with the initial design, the values of SEA, $F_{i p}$, and CFE obtained through optimisation increase by $165.14 \%, 6.92 \%$, and $113.79 \%$, respectively; however, the optimised compression displacement of $305.99 \mathrm{~mm}$ decreases by $46.88 \%$ compared with that under initial design conditions. The optimisation results revealed that the utilisation rate of the structure for materials and impact loads was high, which fails to cause any reduction in energy absorption and instability of crash force. As shown in the increase amplitude of $F_{i p}$, the structure may not result in over-high deceleration. In this sense, the design method used for the structure is preponderant and the optimised composite EAS exerts a significant influence on the crashworthiness of subway vehicles.

\section{Acknowledgment}

This research was undertaken at Key Laboratory of Traffic Safety on Track (Central South University), Ministry of Education, China. The authors gratefully acknowledge the support from the National Natural Science Foundation of China (Grant no. 51775558), the supported by Innovation-Driven Project of Central South University (No. 2018CX023) and the support from the Shenghua Yu-ying Talents Program of the Central South University (Principle Investigator: Prof. Suchao Xie). The corresponding author would like to acknowledge the China Scholarship Council/University of Manchester Joint Scholarship for PhD study (201706370205).

\section{Appendix: The response model expressions}




$$
\begin{aligned}
& S E A=-949.2562 e^{\left[-\left(\left(t_{1}-1.5\right)^{2}+(l-1)^{2}+\left(t_{2}-0.04\right)^{2}\right) / 8\right]}+701.7790 e^{\left[-\left(\left(t_{1}-1.5\right)^{2}+(l-2)^{2}+\left(t_{2}-0.07\right)^{2}\right) / 8\right]}+598.7812 e^{\left[-\left(\left(t_{1}-1.5\right)^{2}+(l-3)^{2}+\left(t_{2}-0.1\right)^{2}\right) / 8\right]} \\
& -1149.4894 e^{\left[-\left(\left(t_{1}-1.5\right)^{2}+(l-4)^{2}+\left(t_{2}-0.13\right)^{2}\right) / 8\right]}+1035.1016 e^{\left[-\left(\left(t_{1}-1.5\right)^{2}+(l-5)^{2}+\left(t_{2}-0.16\right)^{2}\right) / 8\right]}+2291.0571 e^{\left[-\left(\left(t_{1}-2\right)^{2}+(l-1)^{2}+\left(t_{2}-0.07\right)^{2}\right) / 8\right]} \\
& -2297.4196 e^{\left[-\left(\left(t_{1}-2\right)^{2}+(l-2)^{2}+\left(t_{2}-0.1\right)^{2}\right) / 8\right]}+56.7215 e^{\left[-\left(\left(t_{1}-2\right)^{2}+(l-3)^{2}+\left(t_{2}-0.13\right)^{2}\right) / 8\right]}+1241.1849 e^{\left[-\left(\left(t_{1}-2\right)^{2}+(l-4)^{2}+\left(t_{2}-0.16\right)^{2}\right) / 8\right]} \\
& -2598.5402 e^{\left[-\left(\left(t_{1}-2\right)^{2}+(l-5)^{2}+\left(t_{2}-0.04\right)^{2}\right) / 8\right]}-1452.4172 e^{\left[-\left(\left(t_{1}-2.5\right)^{2}+(l-1)^{2}+\left(t_{2}-0.1\right)^{2}\right) / 8\right]}+2625.0468 e^{\left[-\left(\left(t_{1}-2.5\right)^{2}+(l-2)^{2}+\left(t_{2}-0.13\right)^{2}\right) / 8\right]} \\
& -3235.2708 e^{\left[-\left(\left(t_{1}-2.5\right)^{2}+(l-3)^{2}+\left(t_{2}-0.16\right)^{2}\right) / 8\right]}+2703.6099 e^{\left[-\left(\left(t_{1}-2.5\right)^{2}+(l-4)^{2}+\left(t_{2}-0.04\right)^{2}\right) / 8\right]}+1913.4500 e^{\left[-\left(\left(t_{1}-2.5\right)^{2}+(l-5)^{2}+\left(t_{2}-0.07\right)^{2}\right) / 8\right]} \\
& -1667.6270 e^{\left[-\left(\left(t_{1}-3\right)^{2}+(l-1)^{2}+\left(t_{2}-0.13\right)^{2}\right) / 8\right]}+2171.7826 e^{\left[-\left(\left(t_{1}-3\right)^{2}+(l-2)^{2}+\left(t_{2}-0.16\right)^{2}\right) / 8\right]}+363.8051 e^{\left[-\left(\left(t_{1}-3\right)^{2}+(l-3)^{2}+\left(t_{2}-0.04\right)^{2}\right) / 8\right]} \\
& -2427.5173 e^{\left[-\left(\left(t_{1}-3\right)^{2}+(l-4)^{2}+\left(t_{2}-0.07\right)^{2}\right) / 8\right]}-774.1893 e^{\left[-\left(\left(t_{1}-3\right)^{2}+(l-5)^{2}+\left(t_{2}-0.1\right)^{2}\right) / 8\right]}+2154.2208 e^{\left[-\left(\left(t_{1}-3.5\right)^{2}+(l-1)^{2}+\left(t_{2}-0.16\right)^{2}\right) / 8\right]} \\
& -4115.0621 e^{\left[-\left(\left(t_{1}-3.5\right)^{2}+(l-2)^{2}+\left(t_{2}-0.04\right)^{2}\right) / 8\right]}+3274.2119 e^{\left[-\left(\left(t_{1}-3.5\right)^{2}+(l-3)^{2}+\left(t_{2}-0.07\right)^{2}\right) / 8\right]}-1048.0831 e^{\left[-\left(\left(t_{1}-3.5\right)^{2}+(l-4)^{2}+\left(t_{2}-0.1\right)^{2}\right) / 8\right]} \\
& +639.4714 e^{\left[-\left(\left(t_{1}-3.5\right)^{2}+(l-5)^{2}+\left(t_{2}-0.13\right)^{2}\right) / 8\right]}-0.00015694 \\
& C F E=-11.3532 e^{\left[-\left(\left(t_{1}-1.5\right)^{2}+(l-1)^{2}+\left(t_{2}-0.04\right)^{2}\right) / 8\right]}+14.8120 e^{\left[-\left(\left(t_{1}-1.5\right)^{2}+(l-2)^{2}+\left(t_{2}-0.07\right)^{2}\right) / 8\right]}-0.7069 e^{\left[-\left(\left(t_{1}-1.5\right)^{2}+(l-3)^{2}+\left(t_{2}-0.1\right)^{2}\right) / 8\right]} \\
& -7.2826 e^{\left[-\left(\left(t_{1}-1.5\right)^{2}+(l-4)^{2}+\left(t_{2}-0.13\right)^{2}\right) / 8\right]}+5.9566 e^{\left[-\left(\left(t_{1}-1.5\right)^{2}+(l-5)^{2}+\left(t_{2}-0.16\right)^{2}\right) / 8\right]}+26.8433 e^{\left[-\left(\left(t_{1}-2\right)^{2}+(l-1)^{2}+\left(t_{2}-0.07\right)^{2}\right) / 8\right]} \\
& -50.7002 e^{\left[-\left(\left(t_{1}-2\right)^{2}+(l-2)^{2}+\left(t_{2}-0.1\right)^{2}\right) / 8\right]}+21.9695 e^{\left[-\left(\left(t_{1}-2\right)^{2}+(l-3)^{2}+\left(t_{2}-0.13\right)^{2}\right) / 8\right]}+4.5661 e^{\left[-\left(\left(t_{1}-2\right)^{2}+(l-4)^{2}+\left(t_{2}-0.16\right)^{2}\right) / 8\right]} \\
& -12.5050 e^{\left[-\left(\left(t_{1}-2\right)^{2}+(l-5)^{2}+\left(t_{2}-0.04\right)^{2}\right) / 8\right]}-8.7201 e^{\left[-\left(\left(t_{1}-2.5\right)^{2}+(l-1)^{2}+\left(t_{2}-0.1\right)^{2}\right) / 8\right]}+11.5366 e^{\left[-\left(\left(t_{1}-2.5\right)^{2}+(l-2)^{2}+\left(t_{2}-0.13\right)^{2}\right) / 8\right]} \\
& +6.2832 e^{\left[-\left(\left(t_{1}-2.5\right)^{2}+(l-3)^{2}+\left(t_{2}-0.16\right)^{2}\right) / 8\right]}-3.9383 e^{\left[-\left(\left(t_{1}-2.5\right)^{2}+(l-4)^{2}+\left(t_{2}-0.04\right)^{2}\right) / 8\right]}+8.9278 e^{\left[-\left(\left(t_{1}-2.5\right)^{2}+(l-5)^{2}+\left(t_{2}-0.07\right)^{2}\right) / 8\right]} \\
& -21.1077 e^{\left[-\left(\left(t_{1}-3\right)^{2}+(l-1)^{2}+\left(t_{2}-0.13\right)^{2}\right) / 8\right]}+73.9078 e^{\left[-\left(\left(t_{1}-3\right)^{2}+(l-2)^{2}+\left(t_{2}-0.16\right)^{2}\right) / 8\right]}-73.7803 e^{\left[-\left(\left(t_{1}-3\right)^{2}+(l-3)^{2}+\left(t_{2}-0.04\right)^{2}\right) / 8\right]} \\
& +17.3019 e^{\left[-\left(\left(t_{1}-3\right)^{2}+(l-4)^{2}+\left(t_{2}-0.07\right)^{2}\right) / 8\right]}-0.7784 e^{\left[-\left(\left(t_{1}-3\right)^{2}+(l-5)^{2}+\left(t_{2}-0.1\right)^{2}\right) / 8\right]}+18.9962 e^{\left[-\left(\left(t_{1}-3.5\right)^{2}+(l-1)^{2}+\left(t_{2}-0.16\right)^{2}\right) / 8\right]} \\
& -60.2296 e^{\left[-\left(\left(t_{1}-3.5\right)^{2}+(l-2)^{2}+\left(t_{2}-0.04\right)^{2}\right) / 8\right]}+57.0276 e^{\left[-\left(\left(t_{1}-3.5\right)^{2}+(l-3)^{2}+\left(t_{2}-0.07\right)^{2}\right) / 8\right]}-16.0722 e^{\left[-\left(\left(t_{1}-3.5\right)^{2}+(l-4)^{2}+\left(t_{2}-0.1\right)^{2}\right) / 8\right]} \\
& -0.1643 e^{\left[-\left(\left(t_{1}-3.5\right)^{2}+(l-5)^{2}+\left(t_{2}-0.13\right)^{2}\right) / 8\right]}+0.000070585 \\
& F_{i p}=6835.8680 e^{\left[-\left(\left(t_{1}-1.5\right)^{2}+(l-1)^{2}+\left(t_{2}-0.04\right)^{2}\right) / 8\right]}-50974.6406 e^{\left[-\left(\left(t_{1}-1.5\right)^{2}+(l-2)^{2}+\left(t_{3}-0.07\right)^{2}\right) / 8\right]}+43255.6059 e^{\left[-\left(\left(t_{1}-1.5\right)^{2}+(l-3)^{2}+\left(t_{2}-0.1\right)^{2}\right) / 8\right]} \\
& -29657.5978 e^{\left[-\left(\left(t_{1}-1.5\right)^{2}+(l-4)^{2}+\left(t_{2}-0.13\right)^{2}\right) / 8\right]}+4255.0217 e^{\left[-\left(\left(t_{1}-1.5\right)^{2}+(l-5)^{2}+\left(t_{2}-0.16\right)^{2}\right) / 8\right]}+3399.7037 e^{\left[-\left(\left(t_{1}-2\right)^{2}+(l-1)^{2}+\left(t_{2}-0.07\right)^{2}\right) / 8\right]} \\
& +116438.4361 e^{\left[-\left(\left(t_{1}-2\right)^{2}+(l-2)^{2}+\left(t_{2}-0.1\right)^{2}\right) / 8\right]}-70852.9481 e^{\left[-\left(\left(t_{1}-2\right)^{2}+(l-3)^{2}+\left(t_{2}-0.13\right)^{2}\right) / 8\right]}+38845.0350 e^{\left[-\left(\left(t_{1}-2\right)^{2}+(l-4)^{2}+\left(t_{2}-0.16\right)^{2}\right) / 8\right]} \\
& +13541.1670 e^{\left[-\left(\left(t_{1}-2\right)^{2}+(l-5)^{2}+\left(t_{2}-0.04\right)^{2}\right) / 8\right]}-27917.4190 e^{\left[-\left(\left(t_{1}-2.5\right)^{2}+(l-1)^{2}+\left(t_{2}-0.1\right)^{2}\right) / 8\right]}-88906.4254 e^{\left[-\left(\left(t_{1}-2.5\right)^{2}+(l-2)^{2}+\left(t_{2}-0.13\right)^{2}\right) / 8\right]} \\
& +6229.7421 e^{\left[-\left(\left(t_{1}-2.5\right)^{2}+(l-3)^{2}+\left(t_{2}-0.16\right)^{2}\right) / 8\right]}+16230.2918 e^{\left[-\left(\left(t_{1}-2.5\right)^{2}+(l-4)^{2}+\left(t_{2}-0.04\right)^{2}\right) / 8\right]}-39395.7577 e^{\left[-\left(\left(t_{1}-2.5\right)^{2}+(l-5)^{2}+\left(t_{2}-0.07\right)^{2}\right) / 8\right]} \\
& +12260.7972 e^{\left[-\left(\left(t_{1}-3\right)^{2}+(l-1)^{2}+\left(t_{2}-0.13\right)^{2}\right) / 8\right]}+48688.5739 e^{\left[-\left(\left(t_{1}-3\right)^{2}+(l-2)^{2}+\left(t_{2}-0.16\right)^{2}\right) / 8\right]}+8657.6748 e^{\left[-\left(\left(t_{1}-3\right)^{2}+(l-3)^{2}+\left(t_{2}-0.04\right)^{2}\right) / 8\right]} \\
& -20686.4121 e^{\left[-\left(\left(t_{1}-3\right)^{2}+(l-4)^{2}+\left(t_{2}-0.07\right)^{2}\right) / 8\right]}+20295.9443 e^{\left[-\left(\left(t_{1}-3\right)^{2}+(l-5)^{2}+\left(t_{2}-0.1\right)^{2}\right) / 8\right]}+15418.0245 e^{\left[-\left(\left(t_{1}-3.5\right)^{2}+(l-1)^{2}+\left(t_{2}-0.16\right)^{2}\right) / 8\right]} \\
& -47073.2019 e^{\left[-\left(\left(t_{1}-3.5\right)^{2}+(l-2)^{2}+\left(t_{2}-0.04\right)^{2}\right) / 8\right]}+40112.7689 e^{\left[-\left(\left(t_{1}-3.5\right)^{2}+(l-3)^{2}+\left(t_{2}-0.07\right)^{2}\right) / 8\right]}-24575.1546 e^{\left[-\left(\left(t_{1}-3.5\right)^{2}+(l-4)^{2}+\left(t_{2}-0.1\right)^{2}\right) / 8\right]} \\
& +9918.08293 e^{\left[-\left(\left(t_{1}-3.5\right)^{2}+(l-5)^{2}+\left(t_{2}-0.13\right)^{2}\right) / 8\right]}-0.0027
\end{aligned}
$$




$$
\begin{aligned}
F_{\text {avg }}= & -90049.9564 e^{\left[-\left(\left(t_{1}-1.5\right)^{2}+(l-1)^{2}+\left(t_{2}-0.04\right)^{2}\right) / 8\right]}+5072.6960 e^{\left[-\left(\left(t_{1}-1.5\right)^{2}+(l-2)^{2}+\left(t_{2}-0.07\right)^{2}\right) / 8\right]}+151010.6483 e^{\left[-\left(\left(t_{1}-1.5\right)^{2}+(l-3)^{2}+\left(t_{2}-0.1\right)^{2}\right) / 8\right]} \\
& -186903.5460 e^{\left[-\left(\left(t_{1}-1.5\right)^{2}+(l-4)^{2}+\left(t_{2}-0.13\right)^{2}\right) / 8\right]}+105716.6446 e^{\left[-\left(\left(t_{1}-1.5\right)^{2}+(l-5)^{2}+\left(t_{2}-0.16\right)^{2}\right) / 8\right]}+267167.6072 e^{\left[-\left(\left(t_{1}-2\right)^{2}+(l-1)^{2}+\left(t_{2}-0.07\right)^{2}\right) / 8\right]} \\
& -161084.3139 e^{\left[-\left(\left(t_{1}-2\right)^{2}+(l-2)^{2}+\left(t_{2}-0.1\right)^{2}\right) / 8\right]}-103470.2327 e^{\left[-\left(\left(t_{1}-2\right)^{2}+(l-3)^{2}+\left(t_{2}-0.13\right)^{2}\right) / 8\right]}+257555.9588 e^{\left[-\left(\left(t_{1}-2\right)^{2}+(l-4)^{2}+\left(t_{2}-0.16\right)^{2}\right) / 8\right]} \\
& -257887.7089 e^{\left[-\left(\left(t_{1}-2\right)^{2}+(l-5)^{2}+\left(t_{2}-0.04\right)^{2}\right) / 8\right]}-197905.1519 e^{\left[-\left(\left(t_{1}-2.5\right)^{2}+(l-1)^{2}+\left(t_{2}-0.1\right)^{2}\right) / 8\right]}+305740.2096 e^{\left[-\left(\left(t_{1}-2.5\right)^{2}+(l-2)^{2}+\left(t_{2}-0.13\right)^{2}\right) / 8\right]} \\
& -481509.8579 e^{\left[-\left(\left(t_{1}-2.5\right)^{2}+(l-3)^{2}+\left(t_{2}-0.16\right)^{2}\right) / 8\right]}+323578.3181 e^{\left[-\left(\left(t_{1}-2.5\right)^{2}+(l-4)^{2}+\left(t_{2}-0.04\right)^{2}\right) / 8\right]}+137802.4456 e^{\left[-\left(\left(t_{1}-2.5\right)^{2}+(l-5)^{2}+\left(t_{2}-0.07\right)^{2}\right) / 8\right]} \\
& -246955.6966 e^{\left[-\left(\left(t_{1}-3\right)^{2}+(l-1)^{2}+\left(t_{2}-0.13\right)^{2}\right) / 8\right]}+301241.4774 e^{\left[-\left(\left(t_{1}-3\right)^{2}+(l-2)^{2}+\left(t_{2}-0.16\right)^{2}\right) / 8\right]}+187071.3895 e^{\left[-\left(\left(t_{1}-3\right)^{2}+(l-3)^{2}+\left(t_{2}-0.04\right)^{2}\right) / 8\right]} \\
& -376267.3601 e^{\left[-\left(\left(t_{1}-3\right)^{2}+(l-4)^{2}+\left(t_{2}-0.07\right)^{2}\right) / 8\right]}-17173.4284 e^{\left[-\left(\left(t_{1}-3\right)^{2}+(l-5)^{2}+\left(t_{2}-0.1\right)^{2}\right) / 8\right]}+320346.5287 e^{\left[-\left(\left(t_{1}-3.5\right)^{2}+(l-1)^{2}+\left(t_{2}-0.16\right)^{2}\right) / 8\right]} \\
& -573877.7356 e^{\left[-\left(\left(t_{1}-3.5\right)^{2}+(l-2)^{2}+\left(t_{2}-0.04\right)^{2}\right) / 8\right]}+383242.3155 e^{\left[-\left(\left(t_{1}-3.5\right)^{2}+(l-3)^{2}+\left(t_{2}-0.07\right)^{2}\right) / 8\right]}-102457.5937 e^{\left[-\left(\left(t_{1}-3.5\right)^{2}+(l-4)^{2}+\left(t_{2}-0.1\right)^{2}\right) / 8\right]} \\
& +57075.2454 e^{\left[-\left(\left(t_{1}-3.5\right)^{2}+(l-5)^{2}+\left(t_{2}-0.13\right)^{2}\right) / 8\right]}-0.0198
\end{aligned}
$$

\section{References:}

Alavi Nia A, Fallah Nejad K, Badnava H, Farhoudi HR (2012) Effects of buckling initiators on mechanical behavior of thin-walled square tubes subjected to oblique loading. Thin-Walled Structures 59: 87-96.

Alavi Nia A, Parsapour M (2013) An investigation on the energy absorption characteristics of multi-cell square tubes. Thin-Walled Structures 68: 26-34.

Arasomwan MA, Adewumi AO (2013) On the Performance of Linear Decreasing Inertia Weight Particle Swarm Optimization for Global Optimization. The Scientific World Journal 2013: 1-12.

Baroutaji A, Gilchrist MD, Smyth D, Olabi AG (2015) Crush analysis and multi-objective optimization design for circular tube under quasi-static lateral loading. Thin-Walled Structures 86: 121-131.

Chen S, Yu H, Fang J (2018) A novel multi-cell tubal structure with circular corners for crashworthiness. Thin-Walled Structures 122: 329-343.

Chen Y, Bai Z, Zhang L, Wang Y, Sun G, Cao L (2017) Crashworthiness analysis of octagonal multi-cell tube with functionally graded thickness under multiple loading angles. Thin-Walled Structures 110: 133-139.

Clarke SM, Griebsch JH, Simpson TW (2005) Analysis of Support Vector Regression for Approximation of Complex Engineering Analyses. Journal of Mechanical Design 127: 1077-1086.

Coello Coello CA, Mezura Montes E (2002) Constraint-handling in genetic algorithms through the use of dominance-based tournament selection. Advanced Engineering Informatics 16(3): 193-203.

Djamaluddin F, Abdullah S, Ariffin AK, Nopiah ZM (2015) Optimization of foam-filled double circular tubes under axial and oblique impact loading conditions. Thin-Walled Structures 87: 1-11.

Duddeck F, Hunkeler S, Lozano P, Wehrle E, Zeng D (2016) Topology optimization for crashworthiness of thin-walled structures under axial impact using hybrid cellular automata. Structural and Multidisciplinary Optimization 54(3): 415-428.

Esfahlani SS, Shirvani H, Nwaubani S, Shirvani A, Mebrahtu H (2013) Comparative study of honeycomb optimization using Kriging and radial basis function. Theoretical and Applied Mechanics Letters 3(3): 1-5.

Fazilati J, Alisadeghi M (2016) Multiobjective crashworthiness optimization of multi-layer honeycomb energy absorber panels under axial impact. Thin-Walled Structures 107: 197-206. 
Forsberg J, Nilsson L (2005) On polynomial response surfaces and Kriging for use in structural optimization of crashworthiness. Structural and Multidisciplinary Optimization 29(3): 232-243.

Gao Q, Zhao X, Wang C, Wang L, Ma Z (2018) Multi-objective crashworthiness optimization for an auxetic cylindrical structure under axial impact loading. Materials \& Design 143: 120-130.

Hallquist JO (2006) LS-DYNA theory manual. Livermore Software Technology Corporation, California.

Huang F, Wang L, He Q (2007) An effective co-evolutionary differential evolution for constrained optimization. Applied Mathematics and Computation 186(1): 340-356.

Hussein RD, Ruan D, Lu G, Guillow S, Yoon JW (2017) Crushing response of square aluminium tubes filled with polyurethane foam and aluminium honeycomb. Thin-Walled Structures 110: 140-154.

Kohar CP, Mohammadi M, Mishra RK, Inal K (2015) Effects of elastic - plastic behaviour on the axial crush response of square tubes. Thin-Walled Structures 93: 64-87.

Li Z, Duan L, Chen T, Hu Z (2018) Crashworthiness analysis and multi-objective design optimization of a novel lotus root filled tube (LFT). Structural and Multidisciplinary Optimization 57(2): 865-875

Mahdavi M, Fesanghary M, Damangir E (2007) An improved harmony search algorithm for solving optimization problems. Applied Mathematics and Computation 188(2): 1567-1579.

Peng Y, Deng W, Xu P, Yao S (2015) Study on the collision performance of a composite energy-absorbing structure for subway vehicles. Thin-Walled Structures 94: 663-672.

Peng Y, Wang S, Yao S, Xu P (2017) Crashworthiness analysis and optimization of a cutting-style energy absorbing structure for subway vehicles. Thin-Walled Structures 120: 225-235.

Simpson TW, Mauery TM, Korte JJ, Mistree F (2015) Kriging models for global approximation in simulation-based multidisciplinary design optimization. Aiaa Journal 39(12): 2233-2241.

Song X, Sun G, Li G, Gao W, Li Q (2013) Crashworthiness optimization of foam-filled tapered thin-walled structure using multiple surrogate models. Structural and Multidisciplinary Optimization 47(2): 221-231.

Sun G, Huo X, Chen D, Li Q (2017) Experimental and numerical study on honeycomb sandwich panels under bending and in-panel compression. Materials \& Design 133: 154-168.

Sun G, Li G, Gong Z, He G, Li Q (2011) Radial basis functional model for multi-objective sheet metal forming optimization. Engineering Optimization 43(12): 1351-1366.

Sun G, Li G, Stone M, Li Q (2010) A two-stage multi-fidelity optimization procedure for honeycomb-type cellular materials. Computational Materials Science 49(3): 500-511.

Sun G, Li S, Liu Q, Li G, Li Q (2016) Experimental study on crashworthiness of empty/aluminum foam/honeycomb-filled CFRP tubes. Composite Structures 152: 969-993.

Sun G, Zhang H, Fang J, Li G, Li Q (2017) Multi-objective and multi-case reliability-based design optimization for tailor rolled blank (TRB) structures. Structural and Multidisciplinary Optimization 55(5): 1899-1916.

Tan Y, Zhu YC (2010) Fireworks Algorithm for Optimization. In: Tan Y, Shi YH, Tan KC Eds., Lecture Notes in Computer Science, Berlin: Springer-Verlag Berlin, pp 355-364.

Tsai S, Sun T, Liu C, Hsieh S, Wu W, Chiu S (2010) An improved multi-objective particle swarm optimizer for multi-objective problems. Expert Systems with Applications 37(8): 5872-5886.

Wang Z, Tian H, Lu Z, Zhou W (2014) High-speed axial impact of aluminum honeycomb Experiments and simulations. Composites Part B: Engineering 56: 1-8. 
Wang Z, Yao S, Lu Z, Hui D, Feo L (2016) Matching effect of honeycomb-filled thin-walled square tube - Experiment and simulation. Composite Structures 157: 494-505.

Xie S, Zhou H (2015) Analysis and optimisation of parameters influencing the out-of-plane energy absorption of an aluminium honeycomb. Thin-Walled Structures 89: 169-177.

Xie S, Li H, Yang W, Wang N (2018) Crashworthiness optimisation of a composite energy-absorbing structure for railway vehicles. Structural and Multidisciplinary Optimization 57(4): 1793-1807.

Xie S, Zhou H (2014) Impact characteristics of a composite energy absorbing bearing structure for railway vehicles. Composites Part B: Engineering 67: 455-463.

Xie S, Zhou H (2014) Research on the crashworthy structures of subway vehicles. International Journal of Crashworthiness 19(6): 555-566.

Xie S, Zhou H (2014) Multi-objective optimisation of a vehicle energy absorption structure based on surrogate model. Journal of Central South University 21(6): 2539-2546.

Xu P, Yang C, Peng Y, Yao S, Xing J, Li B (2016) Cut-out grooves optimization to improve crashworthiness of a gradual energy-absorbing structure for subway vehicles. Materials \& Design 103: $132-143$.

Yamashita M, Gotoh M (2005) Impact behavior of honeycomb structures with various cell specifications - numerical simulation and experiment. International Journal of Impact Engineering 32(1): 618-630

Yang S, Qi C (2013) Multiobjective optimization for empty and foam-filled square columns under oblique impact loading. International Journal of Impact Engineering 54: 177-191.

Yao S, Xiao X, Xu P, Qu Q, Che Q (2018) The impact performance of honeycomb-filled structures under eccentric loading for subway vehicles. Thin-Walled Structures 123: 360-370.

Yin H, Wen G, Hou S, Qing Q (2013) Multiobjective crashworthiness optimization of functionally lateral graded foam-filled tubes. Materials \& Design 44: 414-428.

Yin H, Wen G, Liu Z, Qing Q (2014) Crashworthiness optimization design for foam-filled multi-cell thin-walled structures. Thin-Walled Structures 75: 8-17.

Yin H, Xiao Y, Wen G, Qing Q, Deng Y (2015) Multiobjective optimization for foam-filled multi-cell thin-walled structures under lateral impact. Thin-Walled Structures 94: 1-12.

Yong D, Wu C, Guo H (2015) Particle swarm optimization algorithm with adaptive chaos perturbation. Cybernetics and Information Technologies 15(6): 70-80.

Yildiz, AR (2009) A novel particle swarm optimization approach for product design and manufacturing. The International Journal of Advanced Manufacturing Technology 40(5-6):617-628.

Zeng D, Duddeck F (2017) Improved hybrid cellular automata for crashworthiness optimization of thin-walled structures. Structural and Multidisciplinary Optimization 56(1): 101-115.

Zhao D, Xue D (2010) A comparative study of metamodeling methods considering sample quality merits. Structural and Multidisciplinary Optimization 42(6): 923-938.

Zhong ZH (1993) Finite element procedures for contact-impact problems. Oxford University Press, Oxford, pp 96-213.

Zhou H, Xu P, Xie S (2017) Composite energy-absorbing structures combining thin-walled metal and honeycomb structures. Journal of Rail and Rapid Transit 231(4): 394-405.

Zhu G, Li S, Sun G, Li G, Li Q (2016) On design of graded honeycomb filler and tubal wall thickness for multiple load cases. Thin-Walled Structures 109: 377-389. 
Zhu P, Pan F, Chen W, Zhang S (2012) Use of support vector regression in structural optimization: Application to vehicle crashworthiness design. Mathematics and Computers in Simulation 86: 21-31. 